NBER WORKING PAPER SERIES

\title{
STRATEGIC POLICY CHOICE IN STATE-LEVEL REGULATION: THE EPA'S CLEAN POWER PLAN
}

\author{
James B. Bushnell \\ Stephen P. Holland \\ Jonathan E. Hughes \\ Christopher R. Knittel \\ Working Paper 21259 \\ http://www.nber.org/papers/w21259 \\ NATIONAL BUREAU OF ECONOMIC RESEARCH \\ 1050 Massachusetts Avenue \\ Cambridge, MA 02138 \\ June 2015
}

The authors thank seminar participants at the Energy Institute at Haas, the Massachusetts Institute of Technology, the University of California at Berkeley and the University of North Carolina at Greensboro. The views expressed herein are those of the authors and do not necessarily reflect the views of the National Bureau of Economic Research. Bushnell's work was supported in part by the National Science Foundation under award 1229008. Bushnell serves on the Market Surveillance Committee to the California Independent System Operator (CAISO). The MSC is an independent advisory committee to the CAISO's Board of Governors.

At least one co-author has disclosed a financial relationship of potential relevance for this research. Further information is available online at http://www.nber.org/papers/w21259.ack

NBER working papers are circulated for discussion and comment purposes. They have not been peerreviewed or been subject to the review by the NBER Board of Directors that accompanies official NBER publications.

(C) 2015 by James B. Bushnell, Stephen P. Holland, Jonathan E. Hughes, and Christopher R. Knittel. All rights reserved. Short sections of text, not to exceed two paragraphs, may be quoted without explicit permission provided that full credit, including $(\mathcal{C}$ notice, is given to the source. 
Strategic Policy Choice in State-Level Regulation: The EPA's Clean Power Plan

James B. Bushnell, Stephen P. Holland, Jonathan E. Hughes, and Christopher R. Knittel

NBER Working Paper No. 21259

June 2015

JEL No. L5,L9,Q48,Q54

\begin{abstract}
Flexibility in environmental regulations can lead to reduced costs if it allows additional abatement from lower cost sources or if policy tailoring and experimentation across states increases regulatory efficiency. The EPA's 2014 Clean Power Plan, which implements greenhouse gas regulation of power plants under the Clean Air Act, allows substantial regulatory flexibility. The Clean Power Plan sets state-level 2030 goals for emissions rates (in lbs CO2 per MWh) with substantial variation in the goals across states. The Clean Power Plan allows states considerable flexibility in attaining these goals. In particular, states can choose whether to implement the rate standards goals or equivalent mass-based goals (i.e., emissions cap and trade, CAT). Moreover, states can choose whether or not to join with other states in implementing their goals. We analyze incentives to adopt inefficient rate standards versus efficient CAT standards using both analytical and simulation models. We have five main results. First, we theoretically show that industry supply can be efficient under both CAT regulation and rate-based regulation. However, under rate-based standards the carbon price must equal the social cost of carbon and the rate standard must be equal across all the states. Second, we illustrate important differences in the incentives of a unified coalition of states and the incentives of a single state. Third, our simulation results show that when states fail to coordinate on a policy, the merit order can be "scrambled" quite dramatically leading to significant inefficiencies. Fourth, the Nash equilibrium of a game between coastal and inland western states is an inefficient policy for consumers and an uncoordinated policy for generators. Finally, we show that how new plants are treated under the Clean Power Plan has large effects on the scale and location of entry.
\end{abstract}

James B. Bushnell

Department of Economics

One Shields Ave.

University of California, Davis

Davis, CA 95616

and NBER

jbbushnell@ucdavis.edu

Stephen P. Holland

Bryan School of Business and Economics

University of North Carolina, Greensboro

P.O. Box 26165

Greensboro, NC 27402-6165

and NBER

sphollan@uncg.edu

An online appendix is available at: http://www.nber.org/data-appendix/w21259
Jonathan E. Hughes

Department of Economics

University of Colorado at Boulder

0256 UCB

Boulder, CO 80309

jonathan.e.hughes@colorado.edu

Christopher R. Knittel

MIT Sloan School of Management

100 Main Street, E62-513

Cambridge, MA 02142

and NBER

knittel@mit.edu 


\section{Introduction}

Within the United States, state-by-state variation in regulatory approaches has been more of the norm than an exception. Within the utility industries, individual state regulatory commissions have used substantially different variations on the rate-of-return regulatory framework, for example, while some states have chosen to rely on wholesale power markets instead of vertically integrated utilities. In the environmental realm, the Federal Environmental Protection Agency (EPA) has often deferred to state or local air quality regulators to develop specific implementation plans to achieve the EPA's environmental mandates. The Clean Air Act, one of the dominant environmental regulatory instruments, requires the EPA to leave regulatory decisions up to individual states.

In electricity markets, the regulatory actions of states, or even local communities, often affect the market outcomes in surrounding areas because electricity flows throughout regional networks. In the climate change policy arena, California and states in the northeastern U.S. have faced this issue with their unilateral adoption of cap-and-trade programs limiting carbon emissions from in-state sources. In both instances, there have been concerns that such actions could spur "leakage" of both emissions and of beneficial economic activity to the neighboring uncapped regions; specifically, while emissions may decrease within the regulatory jurisdictions, emissions may increase elsewhere as output increases from unregulated power plants. ${ }^{1}$

A more subtle form of economic spillovers can arise when individual states respond to regulatory requirements with different instruments. The choice of instrument affects each power plant's opportunity cost of selling electricity. Therefore, certain policies may provide a competitive advantage to power plants within a particular state, and this advantage will depend on the policies adopted in other states. In the face of these incentives, it is not clear the equilibrium outcome will yield the efficient mix of policies.

Recent actions by the EPA to address greenhouse gas emissions create a similar dynamic. In this case however, the stakes are much higher than the examples above. The EPA's "Clean Power Plan" (CPP) proposes major reductions in carbon emissions from electricity generators in the United States (US). Focusing on the electricity sector, the CPP uses existing provisions of the Clean Air Act Amendments to regulate a substantial share of carbon emissions. Due in part to inaction at the federal level, recent US climate policy has been driven almost exclusively by state and regional initiatives. This has raised concerns over inefficiencies from uncoordinated policies (Bushnell, Peterman and Wolfram (2008)). A national

\footnotetext{
${ }^{1}$ See Fowlie (2009) and Chen (2009).
} 
framework holds the potential to decrease inefficiencies created by the patchwork of state and regional policies and could improve US standing in international climate negotiations (Newell, Pizer and Raimi (2012), Stavins (2008)).

The regulatory approach taken by the EPA is, in many ways, unprecedented. The CPP establishes state-level targets for carbon emissions rates in lbs of carbon dioxide per megawatt hour of electricity generated (lbs per MWh). States have a great deal of flexibility in how to achieve these goals. For example, they may adopt the default rate standard or they could adopt an equivalent "mass-based" regulation such as a carbon cap and trade system (CAT). Under a rate standard, the state must decrease its carbon emissions rate, whereas under a mass-based standard the state must decrease its aggregate emissions (e.g., create an emissions cap). Because these systems create different incentives, effects on consumers and producers within a state could be quite different depending on the type of regulation adopted. Because electricity is traded regionally across state lines, these effects depend on both the type of regulation adopted by each state as well as regulations adopted by its trading partners. Furthermore, the states' private incentives may be at odds with those of a national social planner.

We analyze the potential effects of the CPP in terms of electricity market outcomes and state adoption incentives. We first analyze a general theoretical model and then calibrate a simulation model to analyze electricity markets in the western United States.

We have five main results. First, we theoretically show that industry supply, i.e., the merit order, can be efficient under both CAT regulation and rate-based regulation. However, under rate-based standards the carbon price must equal the social cost of carbon and the rate standard must be equal across all the states. Importantly, if carbon prices are equal across states but rate standards are not equal, carbon costs would be different for identical generators in the different states and thus the merit order could be inefficient. Efficiency of supply is a necessary but not sufficient condition for efficiency. In fact, if demand is not perfectly inelastic, we show that only CAT can be efficient. This result echoes earlier results in the literature, e.g., Helfand (1991), Holland, Hughes and Knittel (2009).

Second, we illustrate important differences in the incentives of a unified coalition of states and the incentives of a single state. For the coalition of states, adoption of CAT is best from an efficiency perspective. However, from the perspective of an individual state, adoption of a rate standard (instead of CAT) results in lower electricity prices. This benefits consumers (both in this state and in other states) so consumers have an incentive to lobby for adoption of rate standards. From a generator's perspective, lower electricity prices from adoption of a rate standard could lead to lower profits. However, regulated generators' costs fall by more 
than the electricity prices fall. This leads to a split in incentives for generators. Generators whose operations are not covered by the regulation, e.g., distributed generation, renewables, nuclear, small fossil plants, prefer the high electricity prices associated with CAT. On the other hand, regulated generators (e.g., existing fossil plants) benefit from lower costs and prefer rate standards. Holding carbon prices fixed, we show adoption of a rate standard is a dominant strategy from the perspective of "covered" generators, but adoption of CAT is a dominant strategy from the perspective of "uncovered" generators.

We explore our theoretical predictions using a simulation model for the eleven states in the western interconnection of the U.S. electricity grid simulating a variety of regulation scenarios including: no regulation (business as usual, BAU), a single West-wide CAT standard, a single West-wide rate standard, state-by-state CAT standards, and state-by-state rate standards. We also simulate mixed CAT and rate standards across two coalitions: the Coastal states (CA, OR, and WA) and the Inland states (AZ, CO, ID, MT, NM, NV, UT, and WY). We update the model with current natural gas prices and test the sensitivity of our results to this assumption.

This leads to our third main finding: when states fail to coordinate on a policy, the merit order can be "scrambled" quite dramatically leading to significant inefficiencies. In particular, state-by-state CAT or rate standards result in full-marginal costs (and a merit order) which are substantially different than would result under a west-wide policy. We show the merit order is further distorted when coalitions of states adopt different policies. To estimate welfare effects of the different policies, we first calculate the short-run equilibria under the different scenarios. We analyze changes in consumer surplus, generator profits, carbon market revenue, and calculate the deadweight loss of each scenario based on an estimate of the social cost of carbon. We assume the carbon price under a West-wide CAT equals the social cost of carbon and therefore produces no deadweight loss. Under business as usual, deadweight loss is approximately $\$ 0.69$ billion per year.

The deadweight loss from adopting a West-wide rate standard is about $30 \%$ of the BAU deadweight loss. This is due to electricity prices that are too low relative to the first best resulting in too much consumption of electricity. This lower electricity price implies higher consumer surplus under a rate standard. Perhaps more importantly, our short-run analysis also shows substantial deadweight loss from a failure to coordinate policies. In particular, state-by-state rate standards result in a deadweight loss which is twice that of business as usual, i.e., which is twice as bad as doing nothing. In contrast, the deadweight loss from failures to coordinate on CAT standards is only $30 \%$ of the BAU deadweight loss.

Fourth, we analyze the incentives to form regional trading markets. We consider the 
incentives of the two blocks of states defined above: Coastal and Inland states. Our calculations show that from an abatement cost perspective (the sum of consumer surplus, generator surplus, and any carbon market revenue) the strategic interaction between the regions would result in west-wide adoption of CAT, i.e., CAT/CAT is the "Nash equilibrium". When we look at the individual sets of stakeholders, CAT/CAT is no longer an equilibrium. From a consumer's perspective, the Nash equilibrium would be Rate/Rate, i.e., would result in westwide adoption of a rate standard. The incentives of firms depend on the mix of covered and uncovered generators. From the generator's perspective, we find there is a strong incentive to have different regulatory mechanisms; Cap/Rate and Rate/Cap are both Nash equilibria.

Finally, we analyze investment decisions. At the time of this writing, the extent to which state-level plans may or may not include new plants under their Clean Power Plan compliance strategies has not been resolved. Section 111(d) of the Clean Air Act covers only existing sources. New sources are regulated separately and will have to comply with a source-specific $\mathrm{CO}_{2}$ emissions rate standard. We analyze investment in new combined-cycle gas turbines under an assumption of $10 \%$ demand growth relative to 2007 . Under a CAT system, abatement levels are dramatically lower when new investments are excluded. Under a rate standard, abatement levels are higher when new investments are excluded. Average abatement costs are generally higher when new plants are excluded under CAT. The location of new investment will also depend on the regulatory mix. In general new investment will occur in the rate-standard regions if it is included under the Clean Power Plan, since $\mathrm{CO}_{2}$ emissions from a combined-cycle gas turbine are below the Clean Power Plan standard. Our calculations show that investment swings can be quite dramatic for different changes in the regulatory mix.

This work contributes to the literature on environmental and economic spillovers from local climate policies. The fact that GHG policy has been driven at the local, rather than national level, has long created concern over the geographic limitations of the regulations. Three concerns exist. First, as noted environmental targets can be undermined if production is able to shift away from the jurisdictional reach of the regulator through either leakage or reshuffling of production sources. ${ }^{2}$ Second, the existence of many local regulatory programs is unlikely to lead to the efficient amount of abatement across the regions as marginal abatement costs will not equalize. Third, regulatory action in one area may put firms in that region at a competitive disadvantage relative to firms in unregulated regions. These concerns have been a challenge for regional climate initiatives in the US. More generally, concerns over leakage have been a challenge for international climate agreements. In the crafting of European

\footnotetext{
${ }^{2}$ See Bushnell, Peterman and Wolfram (2008), Fowlie (2009), and Chen (2009).
} 
$\mathrm{CO}_{2}$ market, as well as the now defunct Waxman-Markey bill that would have established a national cap in the United States, much attention has been paid to the "competitiveness" question, which is fundamentally related to how vulnerable domestic producers are to leakage from imports.

Our theoretical model is most closely related to Fischer (2003). Fischer analyzes carbon trading between CAT and rate standards and finds that such trade raises carbon emissions. Our theoretical work extends the work of Fischer by analyzing two components which are necessary for understanding the CPP. First, we explicitly model trading in the product market (electricity) which crucially affects the interactions of the states' policy choices. Second, we analyze the states' adoption incentives for CAT and rate standards. Burtraw, et al. (Burtraw et al., 2015) also simulate electricity system outcomes under the CPP. They show that the choice of allocation policy can mitigate some of the perverse effects of inconsistent state regulatory choices. As we show here, however, states may not find it in their interest to mitigate those effects.

Finally, our work contributes to the literature on rate-based environmental regulation. Holland, Hughes and Knittel (2009) show a rate standard cannot, in general, achieve the efficient allocation of emissions and energy production. ${ }^{3}$ In the case of a national low carbon fuel standard (LCFS) for transportation fuels, Holland, Hughes and Knittel (2009) and Holland et al. (Forthcoming) find the inefficiency is quite large. Average abatement costs are several times greater under an LCFS compared with a CAT system that achieves the same emissions reduction. We make three main contributions to this literature. First, prior work assumes demand for energy is essentially static. Since electricity demand can vary substantially hour to hour, our work explicitly captures time varying demand. Importantly, because different generators are dispatched in different periods depending on demand, mixed regulation may introduce inefficiencies by distorting the merit order. Second, we quantify the efficiency cost of rate standards compared to CAT policies in the electricity sector. While prior theory results imply rate standards are inefficient, we use our calibrated simulation model to estimate the magnitude of these effects. Third, we investigate states' unilateral incentives to adopt rate standards or CAT regulations. Since the EPA rule allows states to choose which system to adopt, understanding these incentives has important policy implications. ${ }^{4}$

Section 2 discusses the Clean Power Plan in more detail and provides policy background. Section 3 develops the theoretical model and derives the theoretical results. Section 4

\footnotetext{
${ }^{3}$ This inefficiency does not arise when rates are calculated using an exogenous base such as historical emissions (Holland, Hughes and Knittel, 2009) or GDP (Pizer, 2005).

${ }^{4}$ See also Holland (2012), Huang et al. (2013), Pizer (2005) and Zilberman et al. (2013).
} 
presents the simulation model and Section 5 describes the results. Section 6 concludes.

\section{The Clean Power Plan: GHG Regulation under the Clean Air Act}

Since the landmark 2007 decision by the U.S. Supreme Court in Massachusetts v. EPA, the EPA has taken several steps to limit GHG emissions under the Clean Air Act (CAA). One significant milestone occurred on June 2, 2014 when the Obama administration released the Clean Power Plan (CPP) proposing to regulate GHG emissions from existing power plants. Rather than following the usual permitting process, the CPP instead uses provisions in Section 111 of the CAA. Section 111 provides a flexible framework for regulation, but also imposes constraints on the types of policies that may be implemented under the CPP.

Regulation under Section 111 requires that the EPA establish "standards of performance" which are defined as as "a standard for emissions of air pollutants which reflects the degree of emission limitation achievable through the application of the best system of emission reduction." The text also requires state-level implementation of the standards.

The Clean Power Plan implements Section 111 by establishing emissions rates (in lbs $\mathrm{CO}_{2}$ per MWh) for each state. ${ }^{5}$ These goals are constructed based on the estimated "best system of emissions reductions" for each state. The states then develop plans for achieving those goals, and the EPA approves the plans.

To estimate the best system of emissions reductions goals for each state, the Clean Power Plan uses four "building blocks" each of which contributes to emissions reductions. The first building block focuses on emissions from coal-fired generation. The second building block focuses on shifting generation from relatively dirty coal-fired plants to relatively cleaner gasfired plants. The third building block requires increased generation from low emissions or zero-emissions generation (e.g., nuclear and renewables). The final (fourth) building block focuses on energy efficiency improvements. Efficiency improvements are treated as equivalent to zero-emissions generation, thus both the third and fourth building blocks reduce the goal's emissions rate by increasing the denominator of the "lbs $\mathrm{CO}_{2}$ per $\mathrm{MWh}$ " goal.

\footnotetext{
${ }^{5}$ It is unclear why the CPP specifies rate standards (i.e., in $\mathrm{lbs}^{\mathrm{CO}_{2}}$ per $\mathrm{MWh}$ ) instead of mass-based goals (i.e., in lbs $\mathrm{CO}_{2}$ ). The rationale is likely that rate standards are synonymous with performance goals as required in Section 111. Comments to the EPA recommend that the CPP publish equivalent mass-based goals for each state.
} 
Each state's emissions reductions goal from the four building blocks was published by the EPA for 2030 with an interim goal for 2020. The goals range across states from less than a 20\% reduction in the emissions rate for North Dakota to over a $70 \%$ reduction in the emissions rate for Washington (see NRDC Summary of EPA's Clean Power Plan). The percent emissions reductions from Building Block 2 (the largest building block) are illustrated in Figure A.1. It is hard to compare the stringency of these different goals across states without knowledge of the marginal abatement cost curves across states. Nonetheless, it is clear that there is substantial variation in goals across states.

The CPP allows states to meet their goals by adopting either a "rate-based standard" or a "mass-based standard," i.e., a cap-and-trade (CAT) policy. The CPP also allows states to join a regional multi-state plan. ${ }^{6}$ However, the CPP neither compels states to adopt a CAT nor compels states to follow a regional approach. This flexibility could allow states to tailor their regulations to better fit their unique circumstances. Alternatively, the flexibility could lead states to adopt inefficient regulations which benefit some stakeholders at the expense of others and lead to significant impacts in other states.

\section{The model}

Consider a model of electricity generation and consumption in multiple states (regions). Let $s$ index the states. Since electricity cannot be economically stored, prices vary across time if demand varies. Let $t$ index hours and assume electricity flows freely across the states so that the electricity price in hour $t$ is $p_{t}$ and is common across all the states. ${ }^{7}$ Total demand at time $t$ is given by $D_{t}\left(p_{t}\right)$, and (net) consumer surplus, $C S$, is found by integrating under the demand curve and summing over $t .{ }^{8}$

Supply in the model comes from a variety of generating units each with a constant marginal cost of generation and a limited capacity. Since the generating units may be regulated differently across states, we differentiate generating units by their location. Let $i$ index the technologies (e.g., coal-fired, combustion turbine, etc.) and $s$ index the states.

\footnotetext{
${ }^{6}$ The CPP states: "A state could adopt the rate-based form of the goal established by the EPA or an equivalent mass-based form of the goal. A multi-state approach incorporating either a rate- or mass-based goal would also be approvable based upon a demonstration that the state's plan would achieve the equivalent in stringency, including compliance timing, to the state-specific rate-based goal set by the EPA."

${ }^{7}$ In the simulations, we extend the model to include transmission constraints.

${ }^{8}$ To analyze the distribution of consumer surplus, $C S_{s}$, across the states, we assume that each state's share of demand is a constant fraction of total demand.
} 
Assume $c_{i}$ is the marginal cost of generating from technology $i ; \bar{q}_{s i}$ is the installed capacity in state $s$ of technology $i$; and $\beta_{i}$ is the carbon emissions rate of technology $i$.

Under a market-based carbon regulation, costs also include carbon costs. Let $\tau$ be the social cost of carbon, and let $r \in\{B A U, C A T, R S\}$ index the carbon regulations: "business as usual," "cap-and-trade," and "rate standards."

Define the full marginal cost, $F M C_{s i}^{r}$, as the sum of the marginal generation plus (private) carbon costs. Below we define the full marginal cost for CAT and rate standards. In the absence of carbon regulation, i.e.., in $B A U$, private carbon costs are zero and $F M C_{s i}^{B A U}=c_{i}$. We also define the full marginal social cost as the marginal generation plus social carbon costs, i.e., $c_{i}+\beta_{i} \tau .{ }^{11}$ Welfare, $W^{r}$, under regulation $r$ is defined as the gross consumer surplus less full social costs, or, equivalently, the sum of net consumer surplus, generator profit, and any carbon market revenue minus carbon damages.

The supply from each technology is determined by comparing the electricity price with the full marginal cost. Generators supply at capacity if the electricity price exceeds their full marginal cost, supply nothing if the price is below their full marginal cost, and supply any amount up to capacity if the price equals their full marginal cost.

The market supply is determined by aggregating the supply from each generation technology. The resulting market supply is a non-decreasing step function which orders the technologies by their full marginal cost. The order of the technologies along the supply curve determines the order in which generation units would be called into service as demand increases and is called the merit order.

The equilibrium electricity price in hour $t$ is found from the intersection of hour $t$ demand and market supply. Specifically, under carbon regulation $r$, the price in hour $t$ is given by:

$$
p_{t}^{r}=\min \left\{p: D_{t}(p) \leq \sum_{s} \sum_{i} \Phi\left(F M C_{s i}^{r} \leq p\right) \bar{q}_{s i}\right\},
$$

where $\Phi$ is an indicator function which takes the value one if the argument is true and zero otherwise. Thus $\Phi\left(F M C_{s i}^{r} \leq p\right)$ is one if $F M C_{s i}^{r} \leq p$, i.e., if technology $i$ is willing to supply at price $p$ and is zero otherwise. The set defined in Eq. 1 is the set of prices for which there is excess supply. The minimum of this set will either be a price at which demand exactly

\footnotetext{
${ }^{9}$ The CPP defines "rate-based standards" and "mass-based standards". We simply refer to "rate standards" and "CAT" throughout.

${ }^{10}$ Below we define additional regulatory environments, e.g., $C A T x$ refers to a state with a CAT when other states may have rate standards.

${ }^{11}$ The full marginal social cost does not depend on the state or the carbon regulation.
} 
equals market supply when all inframarginal generators supply at capacity (i.e., on a vertical portion of the supply curve) or will be a price at which any smaller price would have excess demand (i.e., on a horizontal portion of the supply curve).

Based on these equilibrium prices, we can now characterize the equilibrium generation and profits of each technology. If $q_{s i t}^{r}$ is equilibrium generation in state $s$ from technology $i$ in hour $t$ under regulation $r$, then profits are defined as $\pi_{s i}^{r} \equiv \sum_{t}\left(p_{t}^{r}-F M C_{s i}^{r}\right) q_{s i t}^{r}$ for technology $i$ in state $s$ under carbon regulation $r .{ }^{12}$ Finally, we define equilibrium carbon emissions as Carbon $^{r}=\sum_{s} \sum_{i} \sum_{t} \beta_{i} q_{\text {sit }}^{r}$.

\subsection{Cap-and-trade (CAT) regulation}

We now turn to equilibrium under a cap-and-trade (CAT) regulation limiting total carbon emissions. Let $E_{s}$ be allowable emissions in state $s$ and $p_{c s}$ be the price of tradeable certificates for one unit of carbon emissions in state $s$. It is well known that such a cap-and-trade program raises costs of generators in proportion to their carbon emissions, and thus the full marginal cost of technology $i$ is $F M C_{s i}^{C A T}=c_{i}+\beta_{i} p_{c s}$ in state $s$.

These full marginal costs are illustrated in panel (a) of Fig. 1. The figure shows the marginal costs of four technologies: nuclear $\left(c_{N}\right)$, coal $\left(c_{C}\right)$, gas $\left(c_{G}\right)$, and oil $\left(c_{O}\right)$. As illustrated, the unregulated merit order would be first nuclear, then coal, gas, and finally oil because $c_{N}<c_{C}<c_{G}<c_{O}$. If the emissions rates are such that $\beta_{O}>\beta_{C}>\beta_{G}>\beta_{N}=0$, the carbon regulation increases the full marginal costs of coal-fired generation more than of gas-fired generation due to coal's higher carbon emissions. Thus as illustrated the CAT regulation switches the merit order of coal- and gas-fired generation. Market supply would be found from Fig. 1 by re-ordering the technologies according to their full marginal costs.

If all states adopt CAT regulations, the equilibrium electricity price in hour $t$ is characterized by Eq. 1 with this full marginal cost. Generator profits are given by $\pi_{s i}^{C A T} \equiv$

\footnotetext{
${ }^{12}$ Technically, we define:
}

$$
q_{s i t}^{r}= \begin{cases}\bar{q}_{s i}, & \text { if } F M C_{s i}^{r}<p_{t}^{r}, \\ \bar{q}_{s i} \alpha_{s i t}^{r} & \text { if } F M C_{s i}^{r}=p_{t}^{r}, \\ 0 & \text { if } F M C_{s i}^{r}>p_{t}^{r} .\end{cases}
$$

The equilibrium supply has three cases. If price is above marginal cost, then generation is at capacity. If price is below marginal cost, then generation is zero. If price is equal to marginal cost, we assume that each generator supplies the same fraction of their capacity $\alpha_{s i t}^{r}$, where $0<\alpha_{s i t}^{R}<1$. We define $\alpha_{s i t}^{r}=\frac{D\left(p_{t}^{R}\right)-\sum \sum \Phi\left(F M C_{s i}^{r}<p_{t}^{r}-\epsilon\right) \bar{q}_{s i}}{\sum \sum\left(\Phi\left(F M C_{s i}^{r}<p_{t}^{r}+\epsilon\right)-\Phi\left(F M C_{s i}^{r}<p_{t}^{r}-\epsilon\right)\right) \bar{q}_{s i}}$, where $\epsilon$ is small. Note that $\sum_{s} \sum_{i}\left(\Phi\left(F M C_{s i}^{r}<p_{t}^{r}+\epsilon\right)-\right.$ $\left.\Phi\left(F M C_{s i}^{r}<p_{t}^{r}-\epsilon\right)\right) \bar{q}_{s i}$ is the additional capacity which becomes inframarginal when the price increases from $p_{t}^{r}-\epsilon$ to $p_{t}^{r}+\epsilon$. Only the portion $D\left(p_{t}^{r}\right)-\sum_{s} \sum_{i} \Phi\left(F M C_{s i}^{r}<p_{t}^{r}-\epsilon\right) \bar{q}_{s i}$ of this additional capacity is required. So we assume that each technology on the margin supplies the same proportion of this additional generation. With a carbon policy $\alpha_{s i t}^{r}$ may need to be redefined such that the carbon market clears. 
$\sum_{t}\left(p_{t}^{C A T}-F M C_{s i}^{C A T}\right) q_{s i t}^{C A T}=\sum_{t}\left(p_{t}^{C A T}-c_{i}-\beta_{i} p_{c s}\right) q_{s i t}^{C A T}$. Thus generator profits do not include carbon market revenue, e.g., permits are auctioned not grandfathered, and welfare calculations must account for the carbon market revenue separately.

To complete the characterization of the CAT equilibrium, we describe equilibrium in the market for carbon certificates. Since the supply of permits is fixed at $E_{s}$, demand equals supply in state $s$ when $\sum_{i} \sum_{t} \beta_{i} q_{s i t}^{C A T}=E_{s}$. Note that a higher carbon price $p_{c s}$ decreases carbon emissions, so there exists a carbon price which clears the carbon market.

The above characterization of the market equilibrium under CAT assumes each state has its own independent regulation. The model is readily extended to allow carbon trading between states. If states $s$ and $s^{\prime}$ allow carbon trading, then the price of carbon certificates is equal across both states, i.e., $p_{c s}=p_{c s^{\prime}}$, and the market equilibrium is characterized by $\sum_{i} \sum_{t} \beta_{i} q_{s i t}^{C A T}+\sum_{i} \sum_{t} \beta_{i} q_{s^{\prime} i t}^{C A T}=E_{s}+E_{s^{\prime}}$. It is well known that allowing trading across cap-and-trade programs reduces the cost of achieving the aggregate emissions target. Note that the equilibrium is invariant to the distribution of the cap across the states, i.e., only the aggregate cap is relevant.

\subsection{Rate standard regulation}

Next we characterize equilibrium under a rate standard. A rate standard limits the aggregate carbon emissions per MWh of electricity and can be tradeable (see Holland, Hughes and Knittel (2009)). Let $\sigma_{s}$ be allowed emissions per MWh in state $s$. Any technology whose emissions rate, $\beta_{i}$, exceeds the standard would be required to purchase certificates per MWh based on the amount by which its emissions rate exceeds the standard. Conversely, any technology whose emissions rate is below the standard could sell certificates based on the difference between their emissions rate and the standard. Let $p_{c s}$ be the price of tradeable certificates for one unit of carbon emissions. Thus the rate standard changes the full marginal cost of generators based on whether they are buying or selling permits. In particular, the rate standard changes the full marginal cost of technology $i$ in state $s$ from $c_{i}$ to $c_{i}+\left(\beta_{i}-\sigma_{s}\right) p_{c s}$. Note that full marginal costs may be higher or lower than $B A U$ depending on whether $\beta_{i}-\sigma_{s}$ is positive or negative, i.e., depending on whether a technology buys or sells certificates.

These full marginal costs are illustrated in panel (b) of Fig. 1 for the four technologies. As illustrated, the rate standard reduces the full marginal costs of (i.e., subsidizes) nuclear- and gas-fired generation, but increases the full marginal costs of coal- and oil-fired generation. As with the CAT, the merit order under rate standards as illustrated switches gas and coal, i.e., gas-fired generation is used before coal-fired generation as demand increases. 
If all states adopt rate standards, the equilibrium electricity price in hour $t$ is characterized by Eq. 1 with these full marginal costs. Profits are $\pi_{s i}^{R S} \equiv \sum_{t}\left(p_{t}^{R S}-F M C_{s i}^{R S}\right) q_{s i t}^{R S}=$ $\sum_{t}\left(p_{t}^{R S}-c_{i}-\left(\beta_{i}-\sigma_{s}\right) p_{c s}\right) q_{s i t}^{R S}$. As above we assume that generators are not given permits. However some generators create permits by generating electricity, namely, those relatively clean technologies for which $\beta_{i}<\sigma_{s}$. In this case, the term $-\left(\beta_{i}-\sigma_{s}\right)$ is positive and captures the revenue which would arise from selling carbon credits. Thus the profits capture all revenue streams and there is no carbon market revenue to be accounted for separately.

To complete the characterization of the equilibrium, we describe the market for carbon certificates. The demand for carbon certificates is determined by the amount each technology exceeds the standard and by how much electricity is generated from each technology. For example, demand for certificates in state $s$ from technology $i$ is $\sum_{t}\left(\beta_{i}-\sigma_{s}\right) q_{s i t}^{R S}$ if $\beta_{i}>\sigma_{s}$. Similarly, supply in state $s$ from technology $i$ is $\sum_{t}\left(\sigma_{s}-\beta_{i}\right) q_{s i t}^{R S}$ if $\beta_{i}<\sigma_{s}$. Because demand less supply equals zero in equilibrium, the carbon market equilibrium is characterized by $\sum_{i} \sum_{t}\left(\beta_{i}-\sigma_{s}\right) q_{s i t}^{R S}=0$. Note that a higher carbon price $p_{c s}$ decreases demand and increases supply for carbon certificates, so there exists a carbon price which clears the carbon market. Note also that the equilibrium condition can be written

$$
\frac{\sum_{i} \sum_{t} \beta_{i} q_{s i t}^{R S}}{\sum_{i} \sum_{t} q_{s i t}^{R S}}=\sigma_{s}
$$

which implies that the aggregate carbon emissions rate exactly equals the rate standard in equilibrium.

The model can be readily extended to analyze two states who combine their rate standards through carbon trading. Suppose the states $s$ and $s^{\prime}$ allow carbon certificates to be freely traded between the states. Then the prices of the certificates are equal, i.e., $p_{c s}=p_{c s^{\prime}}$, and the equilibrium condition is that demand across both states equals supply across both states. Setting demand less supply equal to zero, we can characterize the carbon market equilibrium by $\sum_{i} \sum_{t}\left(\beta_{i}-\sigma_{s}\right) q_{s i t}^{R S}+\sum_{i} \sum_{t}\left(\beta_{i}-\sigma_{s^{\prime}}\right) q_{s^{\prime} i t}^{R S}=0$. This equilibrium condition can be written:

$$
\frac{\sum_{i} \sum_{t} \beta_{i}\left(q_{s i t}^{R S}+q_{s^{\prime} i t}^{R S}\right)}{\sum_{i} \sum_{t}\left(q_{s i t}^{R S}+q_{s^{\prime} i t}^{R S}\right)}=\frac{\sum_{i} \sum_{t} q_{s i t}^{R S}}{\sum_{i} \sum_{t}\left(q_{s i t}^{R S}+q_{s^{\prime} i t}^{R S}\right)} \sigma_{s}+\frac{\sum_{i} \sum_{t} q_{s^{\prime} i t}^{R S}}{\sum_{i} \sum_{t}\left(q_{s i t}^{R S}+q_{s^{\prime} i t}^{R S}\right.} \sigma_{s^{\prime}}
$$

which implies that the aggregate carbon emissions rate equals a weighted average of the allowed emissions rates across the states where the weights depend on generation.

In addition to trading carbon, which equates the carbon prices, states may also wish to harmonize their rate standards, i.e., to set $\sigma_{s}=\sigma_{s^{\prime}}$. Note that if states do not harmonize their rate standards, then the full marginal costs of identical generators can be different across 
states even if carbon prices are the same. In order to avoid this additional inefficiency, states would need to harmonize their rate standards as well as to allow carbon trading.

Combining rate standards across states does not have the efficiency justification of combining CAT regulations. Combining CATs across states allows the same aggregate emissions target to be attained at lower cost. Combining rate standards across states does reduce costs, but it also means that the emissions target changes: both the aggregate emissions and the aggregate emissions rate are changed by combining rate standards in two states.

\subsection{Mixed CATs and rate regulation}

Finally, we consider the case of mixed regulation in which some states adopt CATs and other states adopt rate standards. Under the Clean Power Plan proposals, states can choose what type of regulation to adopt and a mixture of CATs and rate standards could result. The model is readily extended to mixed regulation. In particular, the equilibrium electricity price is found from the set defined in Eq. 1 where the full marginal costs are $c_{i}+\beta_{i} p_{c s}$ in a CAT state and $c_{i}+\left(\beta_{i}-\sigma_{s}\right) p_{c s}$ in a rate standard state.

States could allow carbon trading across CATs and rate standards. If state $s$ has a CAT and state $s^{\prime}$ has a rate standard, then trading carbon certificates would equate the price of certificates in each state, i.e., would set $p_{c s}=p_{c s^{\prime}}$. Setting the difference between aggregate certificate demand and supply equal to zero implies that the equilibrium certificate price is characterized by $\sum_{i} \sum_{t} \beta_{i} q_{s i t}^{R S}-E_{s}+\sum_{i} \sum_{t}\left(\beta_{i}-\sigma_{s^{\prime}}\right) q_{s^{\prime} i t}^{R S}=0$. This condition does not have a clear interpretation either as a cap or a emissions rate constraint.

\subsection{Theoretical results}

We next compare the outcomes and adoption incentives under certain conditions for the general model. The proofs of all the results are in the appendix. Section 4 then quantifies the effects and makes additional comparisons with a simulation model in the context of the emissions reductions required under the CPP.

The first result describes conditions under which supply is efficient under the different regulations. We then address efficiency in a corollary.

Result 1. Efficient Supply: The merit order is efficient (full social costs are minimized):

(i): if all states adopt CATs and $p_{c s}$ is sufficiently close to $\tau$ for all s; 
(ii): if all states adopt rate standards, $p_{c s}$ is sufficiently close to $\tau$ for all $s$, and $\sigma_{s}$ is sufficiently close to $\sigma$ for all $s$; or

(iii): if there is mixed regulation, $p_{c s}$ is sufficiently close to $\tau$ for all $s, \sigma_{s}$ is sufficiently close to $\sigma$ for all $s$, and $\left|c_{i}+\beta_{i} \tau-c_{j}-\beta_{j} \tau\right|>\sigma \tau$ for all $i$ and $j$.

This result shows sufficient conditions for the efficiency of supply. Importantly, the sufficient conditions become increasingly stringent across the regulations. For CATs, supply is efficient if the carbon price equals (or is close to) the social cost of carbon.

For rate standards, supply can also be efficient. For a given carbon price, the CAT and rate standard induce the same merit order since $c_{i}+\left(\beta_{i}-\sigma_{s}\right) p_{c s}<c_{i^{\prime}}+\left(\beta_{i^{\prime}}-\sigma_{s}\right) p_{c s}$ if and only if $c_{i}+\beta_{i} p_{c s}<c_{i^{\prime}}+\beta_{i^{\prime}} p_{c s}$ Intuitively, the rate standard can induce the correct relative prices across the technologies because it simply shifts the full marginal costs down by a constant. However, supply efficiency for a rate standard requires that carbon prices equal the social cost of carbon and that the rate standards be equal across states. Note that these sufficient conditions will not be ensured by carbon trading alone but would also require explicit harmonization of the rate standards across states. Thus the sufficient conditions are more strict for rate standards than for CAT.

Surprisingly, Result 1 (iii) shows that mixed regulation can also attain the efficient supply but only under more stringent conditions. This result is illustrated in panel (c) of Fig. 1 for four technologies where some of each technology is subject to a CAT and some is subject to a rate standard of $\sigma$ and the carbon price is $\tau$. Note that within each technology, the implicit subsidy of the rate standard lowers the full marginal cost by $\sigma \tau$, so the rate-standard technology is dispatched first, e.g., gas under the rate standard is dispatched before coal under the CAT. As illustrated, the merit order is efficient, because all the gas-fired generation is used before the coal-fired generation as demand increases.

However, the efficiency of supply only occurs because the full marginal costs are sufficiently different. If the full marginal costs are close, i.e., if $\left|c_{C}+\beta_{C} \tau-c_{G}-\beta_{G} \tau\right|<\sigma \tau$, then the merit order is not efficient. As illustrated in panel (d) of Fig. 1 the full marginal costs are sufficiently close that the merit order is rate-standard gas, followed by rate-standard coal, then CAT gas, and then CAT coal. This merit order is inefficient since the full marginal social cost of gas-fired generation is less than the full marginal social cost of coal. ${ }^{13}$

Result 1 also highlights the importance of coordination across states. For CATs, all carbon prices need to be sufficiently close to $\tau$, which can be ensured by carbon trading and

\footnotetext{
${ }^{13}$ This inefficiency from mixed regulation is limited, because it only arises if full marginal costs are sufficiently close, i.e., if costs are small from the wrong merit order.
} 
a correct overall cap. Note that with carbon trading the distribution of the cap across states is irrelevant. With rate standards, trading can again ensure that carbon prices are equal across states. However, now the standards must be set equally across states in order for the merit order to be efficient, i.e., the distribution of the rate standards across the states is crucial. The result also shows an additional inefficiency if states fail to coordinate on a CAT or a rate standard.

This result also emphasizes the importance of carbon prices. Importantly, efficient supply depends on the carbon price being sufficiently close to $\tau$, but does not depend on the target emissions level or the target emissions rate. Thus, to attain efficient supply, the regulator would need to adjust the emissions cap or target emissions rate to maintain the carbon price equal to $\tau$. Unfortunately, the Clean Power Plan specifies emissions rate targets rather than carbon price targets.

Result 1 shows the increasingly stringent conditions under which the different regulations can lead to an efficient supply, i.e., an efficient merit order. However, efficiency of supply is necessary but not sufficient for overall efficiency of a regulation, as the following corollary makes clear:

Corollary 1. Efficiency: If demand is perfectly inelastic, then CATs, rate standards, or mixed regulation achieve efficiency if the merit order is efficient.

If demand is not perfectly inelastic, then CAT regulations achieve efficiency if $p_{c s}=\tau$ for all s. Rate standards and mixed regulation do not achieve efficiency.

This corollary echoes earlier results in the literature (e.g., see Helfand (1991), Kwoka (1983), Holland, Hughes and Knittel (2009)). If demand is perfectly inelastic, then there is no consumption inefficiency and efficiency only requires efficient supply. However, if demand is not perfectly inelastic, then only a CAT regulation with a carbon price of $\tau$ can attain the first best. ${ }^{14}$

Given the importance of equal carbon prices in Result 1, the next result addresses the benefits from carbon trading, which equates carbon prices across regions.

Result 2. Carbon Trading: Trading carbon between states reduces costs. Trading between states with CATs holds aggregate emissions constant. Trading between states with rate standards may cause aggregate emissions to increase or decrease.

\footnotetext{
${ }^{14}$ Holland (2012) shows that rate standards can attain the first best if they are coupled with an electricity tax of $\sigma \tau$.
} 
This result shows that although carbon trading does reduce costs, it may not have clear efficiency benefits. Under CATs aggregate emissions are held constant and thus a reduction in costs leads to a clear efficiency gain. Under rate standards, aggregate emissions could increase or decrease, and thus the welfare effects are indeterminate.

We next compare the equilibrium outcomes across policies in which all states adopt the same policy. We analyze electricity prices, consumer surplus, and profits to "uncovered generators," namely, generators which are not covered by the regulation, e.g., renewables or distributed generation.

Result 3. Prices, Consumer Surplus, and Uncovered Generator Profits: For $a$ given carbon price $p_{c s}>0$,

(i) electricity prices are higher under CATs than under either rate standards or no regulation, i.e., $p_{t}^{C A T} \geq p_{t}^{R S}$ and $p_{t}^{C A T} \geq p_{t}^{B A U}$, and electricity prices under rate standards or under mixed regulation can be either higher or lower than under no regulation;

(ii) consumer surplus is lower under CATs than under either rate standards or no regulation, i.e., $C S^{C A T} \leq C S^{R S}$ and $C S^{C A T} \leq C S^{B A U}$, and consumer surplus under rate standards or under mixed regulation can be either higher or lower than under no regulation; and

(iii) profits for uncovered generation are higher under CATs than under either rate standards or no regulation, and profits for uncovered generation under rate standards or under mixed regulation can be either higher or lower than under no regulation.

For a given carbon price, this result shows that electricity prices are higher under CATs but can be higher or lower than BAU prices under rate standards. These price comparisons follow from a comparison of the full marginal costs under the policies. Since full marginal costs are higher under CAT than under rate standards or BAU, the electricity price is higher. Similarly, since the full marginal costs under rate standards can be higher or lower than under BAU, the electricity prices are similarly higher or lower. The results on consumer surplus and profits of uncovered generation follow directly from the result on prices.

The result on uncovered generation is important since significant generation capacity may not be covered by the Clean Power Plan, e.g., hydro, nuclear, and some combined heat and power. The result shows that these uncovered generators will prefer CAT regulation because they would benefit from the higher electricity prices. The effect is somewhat different for "dirty" and "clean" uncovered generators. For dirty uncovered generators, the benefit arises from the higher electricity prices and because the lack of carbon regulation does not increase 
their costs. For clean uncovered generators, the difference arises from the higher electricity prices and because the lack of carbon regulation does not decrease their costs under rate standards. The inability to sell carbon credits under a rate standard implies that uncovered clean generation prefers CAT. Note that this result also implies that incentives are strongest under CAT for new clean generation and for efficiency improvements both of which might be uncovered by the Clean Power Plan.

The result also has important implications for investment incentives. Investment will occur in the most profitable locations. New fossil-fuel fired generation may be "uncovered" since it is subject to other regulations, e.g., Section 111(b), and may not be subject to the Clean Power Plan. Renewables and small combined heat and power will also likely not be covered by the Clean Power Plan. The result implies that there would be more investment in uncovered generation under CAT regulation than under rate standards.

We next analyze the incentives for states to adopt either CATs or rate standards. We begin by analyzing the outcomes if states coordinate on either a single CAT or a single rate standard. To focus the analysis, we assume additionally that carbon prices equal $\tau$ and rate standards are equal across states, i.e., we assume that supply is efficient.

Result 4. Adoption Incentives of a Coalition: Suppose that all states adopt the same regulation, i.e., all states have a unified CAT or unified rate standard. Suppose further that the CAT or rate standard results in a carbon price equal to the social cost of carbon across both regimes and across all states, i.e., $p_{c s}=\tau$ for all $s$, and that rate standards are equal across states, i.e., $\sigma_{s}=\sigma$ for every $s$.

(i): $p_{t}^{C A T} \leq p_{t}^{R S}+\sigma \tau$ for all $t$;

(ii): $\sum_{s} \sum_{i} \sum_{t} q_{s i t}^{C A T} \leq \sum_{s} \sum_{i} \sum_{t} q_{s i t}^{R S}$

(iii): $\pi_{s i}^{C A T} \leq \pi_{s i}^{R S}$ for all $s$ and $i$;

(iv): $\sum_{s} \sum_{i} \sum_{t}\left(c_{i}+\beta_{i} \tau\right) q_{s i t}^{C A T} \leq \sum_{s} \sum_{i} \sum_{t}\left(c_{i}+\beta_{i} \tau\right) q_{s i t}^{R S}$

(v): Carbon $^{C A T} \leq \operatorname{Carbon}^{R S}$;

(vi): $W^{C A T} \geq W^{R S} ;$ and

(vii): $T R^{C A T}+\tau\left(\right.$ Carbon $^{R S}-$ Carbon $\left.^{C A T}\right) \geq\left(C S^{R S}-C S^{C A T}\right)+\left(\pi^{R S}-\pi^{C A T}\right)$.

If additionally we assume that demand is perfectly inelastic, then each of the weak inequalities above is an equality.

This result compares the outcomes when states coordinate on CATs or rate standards and all carbon prices equal $\tau$. Much of the intuition of the result comes from the comparison 
of the electricity prices in Result $4(i)$. This result shows that although electricity prices are lower under rate standards, the drop in prices is bounded by $\sigma \tau$. Because full marginal costs are lower by $\sigma \tau$ under rate standards, prices are also lower by exactly this amount if demand is perfectly inelastic. If demand is not perfectly inelastic, then a price which is lower by $\sigma \tau$ could result in excess demand. Thus the price difference is at most $\sigma \tau$.

Because electricity prices are lower under rate standards and the merit order is unchanged, it follows that generation, generation costs, and carbon emissions are higher. Generator profits are also higher under rate standards, despite the lower electricity prices because full marginal costs are lower. Because full marginal costs are lower by $\sigma \tau$ and prices are lower by at most $\sigma \tau$, generator profits increase.

The inefficiency of rate standards, described in Corollary 1, implies the result on welfare in Result 4 (vi). Rewriting this in Result 4 (vii) shows that the sum of carbon market revenue and the increase in carbon market damages exceeds the sum of the increases in consumer surplus and profit under rate standards.

With perfectly inelastic demand this equality becomes $C S^{C A T}+T R^{C A T}=C S^{R S}$, which shows that the gain in consumer surplus from a rate standard is exactly the foregone carbon market revenue $T R^{C A T}$. In this case, the carbon market revenue is exactly sufficient to compensate consumers for the lost consumer surplus under CATs.

If demand is not perfectly inelastic, the inequality in (vii) is much less informative about the ability of carbon market revenue to compensate consumers and producers for their losses under a CAT. In particular, it shows that carbon market revenue plus the additional carbon damages would be sufficient to compensate both producers and consumers for their losses under CAT. However, the result suggests that it is an empirical question whether or not carbon market revenue by itself will be sufficient to compensate both producers and consumers for their losses under CAT.

\subsection{Incentives for Regulatory Choice}

We now turn to the adoption incentives of an individual state. In particular the question of how a state's choice interacts with other states' choices to influence economic outcomes. This question can be directly addressed by the previous results in cases where the carbon prices are exogenous to the specific mechanism. For example if the mechanism were a carbon tax, rather than an emissions cap. 
If carbon prices were exogenous, then Result 4 would be a good guide to the adoption incentives of a single state. ${ }^{15}$ As in Result $4(i)$, if the state adopted a rate standard instead of a CAT, electricity prices would be lower in any hour in which that state's generators were marginal, but the electricity price would be lower by at most $\sigma_{s} \tau$. Since generators' costs would be lower by $\sigma_{s} \tau$, generators' profits would be higher under the rate standard. With lower electricity prices, consumer surplus would also be higher under a rate standard. Thus consumers and covered generators would prefer that their state adopt the rate standard regardless of what other states do. In other words, adoption of a rate standard would be a dominant strategy from the perspective of covered generators or consumers. On the other hand, lower electricity prices and no carbon market revenue imply that CAT adoption would be a dominant strategy from the perspective of government revenues and of uncovered generators. Thus, with fixed carbon prices, some perspectives would have dominant strategy for adoption of a CAT but others would have a dominant strategy for adoption of a rate standard.

Since the Clean Power Plan specifies emissions rates rather than carbon prices, carbon prices are likely to be endogenous to the regulatory choices of neighboring states. This complicates a single state's adoption decision. Most likely endogenous prices increase the potential benefits to states of not coordinating with neighboring states. For example, suppose a state were to consider a CAT when all its neighbors adopt a rate standard. With an exogenous carbon price, the full marginal costs would be higher under the CAT and thus the state's generators would be dispatched less frequently under the CAT. However, when prices are endogenous, the increased imports would lower domestic emissions and hence relax a capped emissions constraint. ${ }^{16}$ This implies that the state's carbon price would be lower if it adopted a CAT instead of an equivalent rate standard. By contrast, a state choosing a rate standard when its neighbors are under CAT could experience either an increase or decrease in its carbon price, depending upon the mix of available supply in that state. For example if the rate state had excess "clean" generation capacity then increasing exports from those clean sources would relax the rate standard constraint and hence lower carbon prices.

With endogenous carbon prices, we can construct an example where adoption of mixed regulations lowers carbon costs for both CAT and rate states. Compliance costs and electricity prices would then be lower compared to a uniform CAT scheme. A state's adoption incentives will hence involve a combination of carbon price effects in addition to the effects outlined in Result 4. To assess the magnitude of these effects, we turn to a numerical

\footnotetext{
${ }^{15}$ Result 5 in Supplementary Appendix A extends Result 4 to analyze the adoption incentives of a single state assuming carbon prices are fixed at $\tau$.

${ }^{16}$ Intuitively, the state can achieve compliance through importing.
} 
simulation model.

\section{$4 \quad$ Numerical simulations}

The theoretical model describes the inefficiencies which can result when states choose CAT regulation or rate standards across an integrated product market. As described above, there are several additional considerations to the actual Clean Power Plan that are difficult to capture in a theoretical model, including the heterogeneity of both supply technologies and emissions limits across states, and importantly, the endogeneity of carbon prices a market's choice of regulatory mechanism. We approach this richer set of issues using numerical simulation methods applied in the context of the electricity market in the western US. We utilize an electricity transmission and supply model similar to that used in Bushnell and Chen (2012) (BC 2010) and Bushnell, Chen and Zaragoza-Watkins (2014) (BCZ 2011). The model has been calibrated using market data from the year 2007. In this section, we present the simulation model and the data used to parameterize the model. Additional details on the numerical simulation are in Online Appendix C

\subsection{Optimization model and constraints}

Because we assume firms act in a manner consistent with perfect competition in both the electricity and emissions permit markets, market equilibrium is equivalent to the solution of a social planner's problem. ${ }^{17}$ Our social planner's problem maximizes gross consumer surplus less generation costs subject to constraints. Using the notation developed above, the planner's objective is thus: ${ }^{18}$

$$
\max _{q_{s i t}} C S+\sum_{s} \sum_{i} \sum_{t}\left(p_{t}-c_{i}\right) q_{s i t}
$$

Maximization of Eq. 3 is subject to generation, transmission, and policy constraints. Generation constraints reflect installed capacity adjusted proportionally for the probability of a forced outage of each unit. ${ }^{19}$ Unit forced outage factors are taken from the generator

\footnotetext{
${ }^{17}$ Although the California market was notorious for its high degree of market power in the early part of this decade, competitiveness has dramatically improved in the years since the California crisis, while the vast majority of supply in the rest of the WECC remains regulated under traditional cost-of-service principles.

${ }^{18}$ The objective does not consider carbon damages, which are addressed through the constraints.

${ }^{19}$ This approach to modeling unit availability is similar to Wolfram (1999) and Bushnell, Mansur and Saravia (2008).
} 
availability data system (GADS) data that are collected by the North American Reliability Councils.

Our transmission constraints replicate centralized locational marginal pricing (LMP). Any LMP price differences are arbitraged away subject to the constraints of the transmissions network. ${ }^{20}$ Our model divides the electricity market in the western U.S. into five transmission regions. Optimization of Eq. 3 is therefore subject to constraints on the flows between these five regions. These constraints are governed by existing line capacities. See Supplemental Appendix C.3 for more detail on our modeling of transmission constraints.

The carbon policies are modeled with additional constraints. BAU is modeled by optimizing Eq. 3 subject to the generation and transmission constraints. Under CAT regulation in state $s$, total emissions in the state must also be less than allowed emissions, i.e., the policy constraint is $\sum_{i} \sum_{t} \beta_{i} q_{s i t} \leq E_{s}$. If two states harmonize their CAT regulations through emissions trading, aggregate emissions across the two states must be less than total allowed emissions. The shadow values of the constraints are the carbon prices that would result from implementation with market mechanisms. Similarly, if state $s$ adopts a rate standard, then the emissions rate in the state must be less than the allowed emissions rate: $\sum_{i} \sum_{t} \beta_{i} q_{s i t} / \sum_{i} \sum_{t} q_{s i t} \leq \sigma_{s}$. If two states harmonize their rate standards, then the constraint is on the aggregate emissions rate. Note that this is equivalent to allowing carbon trading plus harmonizing the allowed emissions rates. The shadow values are again the resulting carbon prices. $^{21}$

\subsection{Market demand}

We model electricity demand in each of four regions for each of 80 representative time periods (20 periods for each of four seasons). ${ }^{22}$ To create the 80 representative time periods, we sort California aggregate generation into 20 bins based upon equal MW spreads between the minimum and maximum generation levels observed in the 2007 sample year. ${ }^{23}$ Demand in the representative time period is based on the mean of electricity prices and consumption within each bin in 2007. To aggregate, we weight each representative time period by the

\footnotetext{
${ }^{20}$ Arbitrage of price differences across locations could be achieved through either bilateral transactions or a more centralized operation of the network.

${ }^{21}$ Below we equivalently write the rate standard constraints as $\sum_{i} \sum_{t} \beta_{i} q_{s i t} \leq \sigma_{s} \sum_{i} \sum_{t} q_{s i t}$ so that the shadow value is in dollars per ton of carbon.

${ }^{22}$ Although hourly data are available, for computational reasons we aggregate these data into representative time periods.

${ }^{23}$ California was the original focus of this work so aggregation is based only on California generation.
} 
number of season-hour observations in each bin. ${ }^{24}$

We assume linear demand where the intercept in each time period is determined by the mean hourly electricity price and consumption. ${ }^{25}$ For electricity prices, we use hourly market prices in California and monthly average prices taken from the Intercontinental Exchange (ICE) for the non-market regions. ${ }^{26}$ For electricity consumption, FERC form 714 provides hourly total end-use consumption by control-area which we aggregate to the North American Electric Reliability Commission (NERC) sub-region level. We apply EIA data on annual consumption by state to calculate the fraction of a region's demand that is attributable to a given state.

Because electricity demand is extremely inelastic, we utilize an extremely low value for the slopes of the linear demand curve. For example, in an early review article Taylor (1975) finds short-run price elasticities of electricity demand for residential consumers on the order of 0.15 with some estimates as high as 0.90 . Commercial and industrial demand elasticities are estimated at 0.17 and 0.22 in the short-run. More recently, Kamerschen and Porter (2004) estimate total electricity demand elasticities in the range of 0.13 to 0.15 using US annual data from 1978 to 2008. Reiss and White (2005) estimate a mean elasticity of 0.39 for households in California while Ito (2014) estimates values consistently less than 0.10. Because the CPP affects the price of energy and approximately half of consumers' rate is related to non-energy charges, such as transmission, the response of consumers to changes in wholesale energy prices is likely even smaller. Therefore, the slope of the demand curve is set so that the median elasticity in each region is $-.05 .^{27}$

\subsection{Fossil-fired generation costs and emissions}

We explicitly model the major fossil-fired thermal units. Reliable data on the production costs of thermal generation units are available due to prior cost-of-service regulation within

\footnotetext{
${ }^{24}$ For example, in spring 2007 there were 54 hours in which California (residual) demand fell in the bin between 6949 and $7446 \mathrm{MW}$. To aggregate, resulting emissions from our representative time period are multiplied by 54 to generate an annualized equivalent total level of emissions.

${ }^{25}$ The intercept is the sum of mean consumption and the product of the mean price and demand slope.

${ }^{26}$ To obtain hourly prices in regions outside of California, we calculate the mean difference by season between the California prices and prices in other regions. This mean difference is then applied to the hourly California price to obtain an hourly regional price for states outside of California. Because demand in the model is very inelastic, the results are not very sensitive to this benchmark price method.

${ }^{27}$ Because the market is modeled as perfectly competitive, the results are relatively insensitive to the elasticity assumption, as price is set at the marginal cost of system production and the range of prices is relatively modest.
} 
the industry. The marginal cost of a modeled generation unit is estimated to be the sum of its fuel and variable operation and maintenance (VO\&M) costs.

Generation marginal costs are derived from the costs of fuel and variable operating and maintenance costs for each unit in our sample. Fuel costs make up the largest share of marginal cost for thermal generation units. We calculate fuel costs for each unit as heat-rate multiplied by regional average fuel price. The marginal cost of each unit is therefore constant up to the capacity of the unit. We use unit average heat-rates and regional average fuel prices taken from the Platts PowerDat dataset. Emissions rates, measured as tons $\mathrm{CO}_{2} / \mathrm{MWh}$, are based upon the fuel-efficiency (heat-rate) of a plant and the $\mathrm{CO}_{2}$ intensity of the fuel burned by that plant.

We examine the western electricity market under two different sets of conditions. We first use actual reported natural gas prices from 2007 to calibrate the model and establish if the simulation reasonably captures production and emissions totals over western states. However, natural gas prices have declined sharply since 2007. This has important implications for estimates of the costs of compliance with the CPP. Therefore, after establishing that the model accurately depicts market equilibrium outcomes using 2007 fuel prices, we re-simulate the market using natural gas prices that are, on average $\$ 2.00 / \mathrm{mcf}$ lower, to better capture current conditions. The results reported here utilize the lower natural gas prices representative of current prices.

In some scenarios, we consider investment in new combined cycle gas turbines (CCGT). Based upon information from the EIA, we assume that the annualized capital cost of a standard new CCGT would be $\$ 100 \mathrm{KW}-\mathrm{yr}$. Operating costs $m c_{s t}$ depend upon our natural gas price assumption and are assumed to be $\$ 48 /$ MWh under 2007 gas prices and $\$ 32 / \mathrm{MWh}$ under current gas prices.

\subsection{Uncovered generation}

Our hourly market data include total demand and hourly production of all fossil-fired generation monitored by the EPA's continuous emissions monitoring system (CEMS). These constitute almost all the units units whose emissions would be regulated under the Clean Power Plan, i.e. covered generation. Unfortunately, we lack data on the hourly production from other sources, namely, renewable resources, hydro-electric resources, nuclear, combined heat and power, and other small thermal resources. We infer aggregate hourly production from these sources from the difference between regional consumption and fossil-fired generation after accounting for net imports. These sources, which consist of production with very 
low or zero marginal costs, are assumed to operate with the same hourly production in all of our simulations. We do not observe imports into an individual state for a given hour. Instead net imports are aggregated to the regional level within the western interconnection (WECC) and approximated from data on the hourly flow over key transmission lines between regions.

Thus we have a detailed picture of the total thermal and non-thermal supply in a region, but not of the hourly composition of the non-thermal output. We must instead infer that from EIA data (Form 860) that provides output by source and state on a monthly basis. Using these data we calculate the monthly average fraction of regional non-thermal generation that comes from each non-thermal source (e.g., nuclear, renewables, etc.) and each state in a region. We apply that fraction to the hourly regional data and simulation results to dis-aggregate those results to the state level.

In some results we disaggregate the outcomes for supply between generation sources covered under the clean power plan and "uncovered" sources. Covered sources include all measured fossil generation which emit $\mathrm{CO}_{2}$. Under CAT these are the only plants that are directly impacted by the regulation. For the CPP, the EPA has proposed a complex formula that gives partial credit for output from nuclear plants and also credit for output from nonhydro renewable sources. Technically such sources may be eligible to earn emissions credit payments by virtue of their emissions rates being below the emissions rate standard. However because of our data limitations we include all non-thermal sources in our "uncovered" category when summarizing the results below.

Similarly, we apply EIA data on annual consumption by state to calculate the fraction of a region's demand that is attributable to a given state. Both of these approximations assume that the hourly distribution of regional non-thermal supply and demand amongst states is the same as the monthly or annual average of those distributions.

Appendix Table A.9 summarizes the generation totals and emissions for each of the states coming from covered and uncovered sources based upon EIA data and compares those data to the results of our simulation. These simulation results assume no $\mathrm{CO}_{2}$ regulation and therefore constitute the "business as usual" case.

\section{Simulation results}

In this section we present simulation results under a variety of possible policy scenarios. In each case, the reductions required by each state are based upon the EPA's targeted reductions for the second "building block" of their abatement estimates. These are the EPA's 
expected carbon savings from re-ordering the generation so that low carbon sources run more frequently and, at least partially, displace higher carbon (e.g., coal) sources. We focus on this building block for two reasons. First, this building block captures the largest emissions reductions. Second, simulating the other building blocks requires further assumptions about energy efficiency improvements and investment in future generation. ${ }^{28}$ The second building block requirements vary widely by state, ranging from the $40 \%$ reduction in emissions intensity for Arizona to no reductions at all from Montana and Idaho. These emissions reductions are illustrated in Appendix Figure A.1. Following the theory model, we begin by discussing supply-side effects of regulations on the generation merit order. Then, we analyze short-run equilibrium outcomes under each policy and incentives to form coalitions. Finally, we explore incentives for investment in new capacity under different regulations.

\subsection{Supply-side effects}

We first illustrate the effects of the regulation on the market supply functions. Instead of comparing the market supply curves for different regulations, we illustrate the market supply curve for one regulation and then show the full marginal costs for each generation unit under different regulations. The market supply (or merit order) under the different regulations could be determined by "re-sorting" the generating plants along the x-axis.

Figure 2 compares the full marginal costs of fossil-fuel generation units under West-wide CAT and rate standards to the market supply under BAU (i.e., the generating units are sorted along the x-axis by BAU marginal costs). The generating units to the left of 23 GW are coal-fired and the generating units to the right of $23 \mathrm{GW}$ are gas-fired. The CAT standard (West-wide CAT) increases the full marginal costs of the units in proportion to their carbon emissions. Thus CAT changes the merit order so that some gas-fired generation is cheaper than coal-fired generation, i.e., the gas-fired generation would be used first as demand increases.

The rate standard (West-wide standard), increases the full marginal costs of the coalfired generation because these plants have emissions rates which are worse than the standard. However, the rate standard decreases the full marginal costs of most of the gas-fired generation because these plants have emissions rates which are better than the standard.

This figure illustrates the high correlation between the merit orders under West-wide CAT and rate standards. This correlation illustrates the theoretical result that both CAT

\footnotetext{
${ }^{28}$ In the west, the CPP requires an average reduction of $36 \%$ in the emissions rate. Of this, the four building blocks contribute $4 \%, 15 \%, 9 \%$, and $9 \%$ respectively.
} 
and rate standards can eliminate the supply-side inefficiency by correcting the merit order. However, although the relative costs of the technologies can be correct, the figure shows that full marginal costs are too low under the rate standard. ${ }^{29}$

Figure 3 illustrates the merit order that arises if states fail to harmonize their CAT standards. The figure illustrates the supply curve for a CAT standard (West-wide Cap) and compares it with state-by-state CAT standards (State CATs). The state-by-state caps lead to full marginal costs which are too high in some states - those with tight caps - and too low in other states - those with loose caps. This heterogeneity "scrambles" the merit order and is an additional source of inefficiency. ${ }^{30}$ Practically speaking, this can lead to very different dispatch behavior of similar generating units, which is clearly inefficient.

Figure 4 illustrates the merit order when regional coalitions fail to coordinate policies. This figure compares a West-wide CAT with mixed regulation in which coastal states adopt a CAT standard and inland states adopt a rate standard. The merit order is scrambled so effectively with mixed regulation that almost all the inland plants have lower full marginal costs than any of the coastal plants! Of course, transmission constraints would prevent such an extremely inefficient dispatch, so estimating the inefficiency of these scrambled merit orders requires calculating the equilibria under the various regulations.

\subsection{Short-run equilibria}

There are many metrics one could use to evaluate the impacts of these regulations. We focus on the standard economic metrics of consumer surplus, producer profits, abatement, abatement costs, and deadweight loss. ${ }^{31}$

We next analyze short-run equilibria across different policy types in nine different scenarios. ${ }^{32}$ Scenario 0, represents no regulation, i.e. BAU, establishes a baseline level of costs and emissions by simulating the western market without any GHG regulations. Scenarios 1 through 8 vary which states operate under CAT and rate standards.

We first investigate effects across the different policy types. The odd numbered scenarios assume states operate under the same CAT or rate standard, and can therefore trade across

\footnotetext{
${ }^{29}$ Again, we assume the cap is set optimally such that full marginal costs under CAT are efficient. Under the rate standard, full marginal costs are lower than those under CAT and are often less than the unregulated case where carbon emissions are unpriced.

${ }^{30}$ Appendix Figure A.4 shows a similar "scrambling" of the merit order due to state-by-state rate standards.

${ }^{31}$ Recall, we define abatement cost as the sum of consumer surplus, producer surplus, and any carbon market revenue.

${ }^{32}$ Below we allow investment in new generation capacity.
} 
state lines to achieve the required emissions reductions. In Scenario 1, western states operate under a single CAT standard. Scenario 3 assumes a single standard for all states. Scenario 5 models a single CAT for coastal states and a single rate standard for inland states. ${ }^{33}$ Scenario 7 assumes the opposite, coastal states have a rate standard, while inland states are regulated with CAT.

Next, we explore the effects of policy coordination. The even numbered scenarios assume each individual state has their own CAT or rate standard. In Scenario 2, each state has a state-specific emissions CAT system. Scenario 4 assumes state-specific rate standards. Scenario 6 assumes inland states have state-specific rate standards, while coastal states operate under a single CAT. Finally, Scenario 8 assumes coastal states have different rate standards, while inland states have a single CAT standard.

Table 1 reports equilibrium prices, profits, and changes in welfare across the different scenarios. In Scenario 1, prices increase by roughly $\$ 20$ per MWh, relative to business-asusual, under a single western-states CAT. The quantity of electricity consumed falls by 3 percent, while emissions fall by 17 percent, implying that changes in the merit order are largely driving emission reductions. ${ }^{34}$ The equilibrium permit price, reflecting the price of carbon, is roughly $\$ 35$ per metric ton of $\mathrm{CO}_{2}$. We note this closely matches the social cost of carbon used by the EPA in regulatory filings.

We next calculate the change in consumer and producer surplus prior to any redistribution of carbon permit revenue. We compute the change in consumer surplus and the producer surplus of power plants regulated under the CPP — "covered" plants - and plants that are not regulated under the CPP_ "uncovered" plants. Consumer surplus falls by $\$ 14.14$ billion under a single western CAT system. The producer surplus of plants regulated under the CPP falls by $\$ 2.48$ billion, while profits of uncovered plants increase by roughly $\$ 6.36$ billion. Producer surplus rises for these plants because electricity prices increase and uncovered plants are not required to pay additional carbon costs. The net impact, therefore, on producer surplus is an increase of approximately $\$ 4$ billion. Profits from transmission decrease slightly relative to business as usual. Despite the reduction in generation, production costs increase slightly due to changes in the merit order. The implied carbon market revenue for permit sales exceeds $\$ 9$ billion.

\footnotetext{
${ }^{33}$ Coastal states are California, Oregon and Washington. Inland states are Arizona, Colorado, Idaho, Montana, New Mexico, Nevada, Wyoming and Utah.

${ }^{34}$ We note that this is in contrast to Holland, Hughes and Knittel (2009) and Holland et al. (Forthcoming) which find that, within transportation, the majority of emission reductions come from lowering fuel consumption as opposed to shifting to lower greenhouse gas emitting fuels (ethanol). This is due, in part, to our demand elasticity of 0.05 compared to 0.50 in their baseline simulations.
} 
The abatement cost of emission reductions is $\$ 1.15$ billion, resulting in an average abatement cost of $\$ 21.95$ per ton of $\mathrm{CO}_{2}$. In calculating deadweight loss, we assume the reductions required by EPA accurately reflect the social cost of carbon. In other words, we assume the social costs of carbon are equal to the marginal abatement costs under the most efficient form of abatement, a west-wide CAT system. ${ }^{35}$ Therefore Scenario 1, a west-wide CAT program, produces zero deadweight loss, by definition. ${ }^{36}$ The drop in carbon damages necessarily exceeds abatement costs by $\$ 0.69$ billion - the deadweight loss under no regulation. ${ }^{37}$

This scenario serves as a baseline to compare alternative regulation regimes. The next regulatory regime, Scenario 2, assumes that each state operates under their own CAT system. Therefore, this scenario will not necessarily equate marginal abatement costs across the states. Electricity prices increase slightly compared to a single cap, from $\$ 59.80$ to $\$ 68.17 /$ MWh. By definition, emission reductions are the same, but average permit prices increase by roughly $\$ 9 / \mathrm{MT}^{38}$

Consumers are harmed by state-level CAT systems, given the higher prices, but firms are better off. Profits of covered plants fall by $\$ 0.72$ billion compared to $\$ 2.44$ billion under a single CAT system and producer surplus of uncovered plants increases by $\$ 9.21$ billion or about $\$ 3$ billion more than under CAT. The increase in production cost is slightly less under the multiple CAT standards, while abatement costs are slightly higher. The average abatement cost is roughly $\$ 3.50$ per metric ton greater compared to a single CAT standard. While less efficient than a single CAT, multiple state CAT systems reduce the amount of deadweight loss by approximately 75 percent compared to no regulation.

We next analyze rate standards. Scenario 3 imposes a single rate standard for the western states. Under a single rate standard electricity prices rise slightly compared to no regulation. Abatement is slightly greater than under CAT. The shadow value of emission reductions is $\$ 47.91$ per metric ton. The higher electricity prices decrease consumer surplus slightly, producer surplus decreases for covered but increases for uncovered plants. The average abatement costs increase by 16 percent compared to a single CAT system. Finally, deadweight loss decreases by 75 percent compared to no regulation.

In our simulations, state-specific rate standards create massive inefficiencies. Average electricity prices increase to $\$ 85 / \mathrm{MWh}$, an unrealistically high level compared with

\footnotetext{
${ }^{35}$ In other words, we assume the emissions cap is optimally set.

${ }^{36}$ The implied cost of carbon is $\$ 35.10$ which is well within the range of estimates of the social cost of carbon and similar to the EPA's assumed SCC of $\$ 37 / \mathrm{MT}$ of $\mathrm{CO}_{2 e}$.

${ }^{37}$ The other scenarios, including no regulation, produce some deadweight loss either due to inefficient levels of emissions or excessive abatement costs.

${ }^{38}$ We report the weighted-average electricity price and permit price, weighted by state-level consumption.
} 
$\$ 40.38 / \mathrm{MWh}$ in the unregulated case, Scenario 0. This leads to much larger emission reductions compared to first best, a drop of 75.16 million metric tons versus a drop of 52.45 million metric tons. The shadow value of emission reductions increases dramatically to approximately $\$ 287.64$ per metric ton. The higher prices lead to lower consumer surplus and higher profits compared to either no regulation or a single CAT. Average abatement costs are nearly double those of a single CAT standard. More importantly, social welfare falls under multiple rate standards by $\$ 1.24$ billion compared to first best and by $\$ 0.55$ billion compared to no regulation $(\$ 1.24 \mathrm{~B}$ to $\$ 0.69 \mathrm{~B})$.

Our next set of scenarios model either the coastal or inland states forming a CAT coalition while the remaining states adopt state-level or a single rate standard. These simulations will in turn help us understand the incentives these two coalitions might have to join a westernwide CAT program. Scenario 5 assumes a coastal-state-wide emissions CAT and a single rate standard for inland states. Under this scenario average electricity prices are $\$ 53.65 / \mathrm{MWh}$, falling between the West-wide CAT and West-wide rate scenarios. Emissions fall by 49.04 MMT of $\mathrm{CO}_{2}$, compared to 52.45 MMT under the West-wide CAT scenarios and 75.16 MMT under the state-specific rate standards. Permit prices are $\$ 33.23 / \mathrm{MT}$ in the CAT market, lower than the West-wide CAT, while the shadow value of the rate constraint is $\$ 89.40 / \mathrm{MT}$, considerably higher than under a west-wide rate. Both consumer surplus falls while producer surplus increases for both covered and uncovered generation. There is little carbon market revenue $(\$ 1.78 \mathrm{~B})$ consistent with fewer coastal emissions covered by the CAT system. Most importantly average abatement costs are higher than a West-wide CAT despite the fact that abatement is lower. Furthermore, a considerable amount of deadweight loss remains; deadweight loss falls by only 50 percent relative to the unregulated case.

Scenario 6 replaces the single inland rate-standard with state-specific standards. Not surprisingly average prices increase considerably, as does abatement. We find that such a scenario increases deadweight loss by 13 percent, relative to the unregulated case though average abatement costs are not as high as scenario 4 (state-specific rate standards for every state).

Our final two scenarios assume that coastal states adopt either a single rate standard or state-specific standards, while inland states adopt a single CAT. Given that California currently has a cap-and-trade system in place, we do not believe our last two scenarios are realistic, but they provide the basis for understanding the complete set of incentives. Interestingly, we find that an inland CAT system with rate standards in the west dominates the coastal CAT system combined with inland rate standards. That is, welfare improves more under these scenarios than under scenarios 5 and 6 . 
We next turn to state-specific welfare changes. Table 2 calculates the welfare changes for each state, as well as the two blocks of states discussed above, under each of the scenarios. We assume that carbon-market revenues are returned to consumers and producers in a lumpsum fashion. This table makes clear the divergent incentives of coastal and inland states. The coastal states prefer a single rate standard, Scenario 3, while inland states are most harmed by such a standard. The intuition for this result is that coastal generation sources are, on average, cleaner than inland generators. Therefore under a single rate standard, more coastal generators are implicitly subsidized, while more inland generators are taxed, giving coastal power plants a competitive advantage when the market operates under a single rate standard. Notice that state-specific rate standards (Scenarios 4 and 6) do not lead to such a competitive advantage.

Table 3 focuses on changes in producer surplus. Here the incentives across states are more aligned, since producer surplus depends heavily on equilibrium electricity prices. Producers in both coastal and inland states prefer state-specific rate standards, which as we have shown leads to large increases in the price of electricity. Across Scenarios 5 through 8, each block of states prefers to face state-specific rate standards, but we find that coastal generators benefit, relative to business-as-usual in each of these scenarios.

\subsection{Incentives to form a West-wide coalition}

Our simulations suggest that efficiency is enhanced when states form regional trading markets. A natural question, then, is whether states will have the incentive to form such a coalition? We analyze the incentives of the two blocks of states defined above: coastal and inland states. This division is somewhat reflective of current policy discussions.

Table 4 is the normal form representation of the change in abatement cost or private surplus (ignoring transmission revenues and carbon damages) across the two regions. CAT adoption yields carbon market revenue and tends to benefit uncovered generation but harm consumers and covered generators. The social-surplus perspective assesses whether the benefits outweigh the harms, and hence whether it is possible to compensate losers and to align incentives. As shown, the inland region gains from adopting CAT, regardless of the regulation in the coast. For the coastal region, gains outweigh losses if the inland has a CAT, but not if inland has a rate standard. Thus, the best regulation for the coast depends on the regulation in the inland region. The "Nash equilibrium" is the efficient regulatory mechanism: CAT/CAT (i.e., Coastal CAT/Inland CAT). ${ }^{39}$ Thus it is possible according to our

\footnotetext{
${ }^{39}$ Appendix Figure A.7 shows the state-by-state distribution of the abatement costs. Although the inland
} 
calculations to compensate losers and to align incentives for a West-wide CAT coalition.

When we look at the individual sets of stakeholders, CAT/CAT is no longer an equilibrium. Table 5 presents the payoff matrix to consumers. If carbon prices were unaffected, consumers would prefer rate standards. This generally holds except when inland states adopt a CAT. In this case, adoption of the rate standard increases the carbon price from $\$ 35.10$ to $\$ 190$ (!) in the coastal states. Since this carbon price causes higher electricity prices, coastal consumers would prefer a CAT if inland states adopt a CAT. Nonetheless, if consumers choose the regulatory mix, the Nash equilibrium would be Rate/Rate, i.e., a West-wide rate-standard coalition.

These first two results imply that if left to the social planner, or to consumers, the regulatory mechanism would be the same across the coalition: CAT/CAT if the planner and Rate/Rate if consumers. As we have seen from Table 1, this has important implications for economic efficiency. ${ }^{40}$

The incentives of firms differ dramatically. Table 6 represents the change in profits across both covered and uncovered generators. ${ }^{41}$ If carbon prices were unaffected, covered generators would generally prefer rate standards and uncovered generators would generally prefer CAT. Thus any outcome is possible depending on the relative importance of covered and uncovered generators. We see that there is a strong incentive to have different regulatory mechanisms; CAT/Rate and Rate/CAT are both Nash equilibria. ${ }^{42}$

Several points are worth noting. First aggregate profits are much higher to generators under mixed regulation. Thus a firm with generation in both regions could have an incentive to support rate standards in one region but CAT in the other. Second, if there is a CAT inland, then both covered and uncovered generation would benefit from a rate standard. Similarly, if there is a rate standard inland, both covered and uncovered generation would benefit from a CAT. Thus generators' incentives align for the Rate/CAT equilibrium due to

states as a group always gain from adopting CAT, not all states gain. For example, ID would be harmed more by adopting a CAT standard if the coastal states also adopt CAT than if the inland states adopted a rate.

${ }^{40}$ The consumer's perspective is also illustrated in Appendix Figure A.8 for the individual states. This figure shows the dominance of Rate/Rate from the consumer's perspective. In particular, it illustrates the losses for California consumers under CAT.

${ }^{41}$ Appendix Figure A.9 illustrates changes in generator profits for individual states. Appendix Table A.10 shows profit for covered generators and Appendix Table A.11 shows profit for uncovered generators.

${ }^{42}$ Appendix Table A.10 and Appendix Figure A.10 focus on the profits of covered generators. Once again we find that only disparate regulation is a Nash equilibrium, but we can narrow the equilibrium to Rate/CAT, which curiously is an unlikely outcome given that California has already established a CAT program. We find the same unique Nash equilibrium (in pure strategies) when we look at the profits of uncovered generation in Appendix Table A.11 and Appendix Figure A.11. 
its exceptionally high electricity prices $(\$ 61.38)$. Finally, given the failure of the West-wide

coalition, generator profits are much higher in the region with a rate standard. This would imply the potential for a first-mover advantage if either one of these regions could commit to choosing a rate standard or a first-mover disadvantage if one of the regions has committed to a CAT.

Combined, these results imply that there is very little incentive for formation of a Westwide CAT coalition. While the Nash equilibrium from the social planner's perspective is a West-wide CAT coalition, consumers prefer a West-wide rate standard coalition, and generators prefer mixed regulation. Thus incentives are not aligned across market participants for the formation of the efficient West-wide CAT coalition.

\subsection{Entry incentives}

Another important dimension over which states and the EPA will need to evaluate their compliance plans is the treatment of newly constructed fossil-fired power plants. Technically, Section 111d of the Clean Air Act covers only existing sources. New sources are regulated separately and will have to comply with a source-specific $\mathrm{CO}_{2}$ emissions rate standard. At the time of this writing, the extent to which state-level plans may or may not include new plants under their Clean Power Plan compliance strategies has not been resolved.

We examine this question by adjusting our baseline simulations in two ways. First we anticipate demand growth by escalating hourly demand for every state by 10\% over 2007 levels. Second, we allow firms in each state the option of constructing new combined cycle gas turbines (CCGT). As described previously, these plants are assumed to cost $\$ 100 \mathrm{kw}-\mathrm{yr}$, with a marginal cost of $\$ 32 / \mathrm{MWh}$ at current gas prices. They have an assumed emissions rate of .428 tons/MWh. We assume these costs do not differ across states.

The specification of the investment decision was described in section 4. Essentially, new MW of CCGT capacity are added when the sum of the net revenues (net of MC) exceeds the $\$ 100 \mathrm{KW}$-yr threshold. Capacity is added until such investments just break even. Last we assume that under every environmental regulation scenario, the emissions goal is set equivalent to those established in our baseline simulations without new entry.

The efficiency effects of the different scenarios with investment are shown in the supplementary online materials. Specifically, Appendix Table A.12 presents equilibrium outcomes when new investment is included under the CPP. Appendix Table A.13 presents results when 
new investment is excluded. In general, we see that the average abatement cost is much lower if new investment is included in the CPP. This is true under both CAT and rate standards. ${ }^{43}$

Of course the net revenues of such investments will depend upon the regulatory treatment of not just new sources but also of existing sources. Table 7 summarizes the total additional new CCGT capacity that would be added in each region (coastal or inland), under different combinations of regulatory policies and policies toward new generation. Because of demand growth, there is new investment under every scenario. If we assume that the EPA targets are optimal, then the scenario with all states and new units under CAT would produce the firstbest outcome. Relative to this, excluding new plants from the CAT regulation substantially increases the amount of new CCGT capacity from about 3716 MW to 6353 MW. Conversely, new investment is $5977 \mathrm{MW}$ when new gas capacity is included under a rate standard, and this declines to 4520 MW when new capacity is excluded.

When we examine the mix of regulations, the contrary incentives provided by the two regulations are highlighted. In general, excluding new plants encourages investment under CAT and discourages it under rate standards. When new plants are included, investment is favored under rate standards relative to CAT. When the coastal states adopt CAT and the inland states adopt rate standards, this influence is magnified. Despite an underlying economic benefit of coastal investment, when new plants are included under the regulations all new investment occurs in the inland states, which are operating under a rate standard. When new plants are excluded, this influence reverses and much of the new investment migrates back to the coastal states. However, $3543 \mathrm{MW}$ of new capacity is also built in the rate states, essentially for export back to the coastal states. Overall, under this scenario 9471 MW of new gas capacity are constructed, almost triple that of what could be considered the first-best level.

\section{Conclusion}

There are many contexts in which environmental regulation and trade can interact to undermine the efficiency of both. The EPA's Clean Power Plan is a clear and timely example of these interactions. The CPP proposes major reductions in carbon emissions from generators of electricity, a good that is perfectly substitutable across neighboring states. The CPP establishes state-level targets for carbon emissions rates in lbs of carbon dioxide per megawatt

\footnotetext{
${ }^{43}$ If new investment is included in the $\mathrm{CPP}$, average abatement costs are $\$ 24.62$ per $\mathrm{MT}$ of $\mathrm{CO}_{2}$ under CAT and $\$ 27.42$ per $\mathrm{MT}$ of $\mathrm{CO}_{2}$ under a rate standard. If new investment is not included in the CPP, average abatement costs are $\$ 35.60$ per $\mathrm{MT}$ of $\mathrm{CO}_{2}$ and $\$ 31.07$ per $\mathrm{MT}$ of $\mathrm{CO}_{2}$ under CAT and rate standards.
} 
hour of electricity generated. States have a great deal of flexibility in how to achieve these goals. Because this flexibility creates different incentives, effects on consumers and producers within a state could be quite different depending on the type of regulation adopted both in that particular state as well as in other states because electricity is traded regionally across state lines. Furthermore, the states' private incentives may be at odds with those of a social planner.

In this paper we have focused on the two likely market-based regulatory approaches that could be adopted by states, a mass-based (CAT) approach, and a rate standard. Our theoretical findings imply that efficiency is most likely achieved under CAT, and that a mix of CAT and rate standards is likely to create an inefficient "ordering" of generation resources. Further we find that, while consumers in each state may prefer to coordinate on rate standards, producers can prefer to coordinate on inconsistent regulations, where different states adopt different approaches.

We investigate the importance of our theoretical findings using numerical simulations of the electricity market in the western United States. We find lack of coordination, when states independently pursue their own emissions targets without regard to electricity trading partners, leads to large inefficiencies. For example under state-specific caps, average abatement costs are 16\% higher than under a uniform CAT standard. Under state-specific rate standards, average abatement costs can nearly double relative to a uniform CAT standard. Regional cooperation does little to mitigate these concerns. When two regions of the west coordinate internally, but adopt different instruments, average abatement costs remain 17-29\% higher than costs under a uniform CAT standard. Unfortunately, we find generator incentives do not favor coordination and may lead to adoption of less efficient mixed policies.

One unresolved aspect of the CPP is whether new natural gas generation is included in state emission rates. We examine the implications of the $\mathrm{CPP}$ on the construction of new natural gas generation under a medium-term outlook where demand grows by $10 \%$ relative to 2007 levels. We find that whether new plants are covered under the CPP can dramatically change where new plants are built. When new plants are included in CPP compliance new generation shifts out of CAT regions toward rate regions.

Overall, our findings indicate that despite the opportunities the CPP provides for states to coordinate and implement compliance plans that can efficiently achieve their joint targets, the incentives of individual states to participate in those plans are conflicted. Indeed, there can easily be circumstances when states find it in their own interest to adopt a regulatory approach that is contrary to those of its neighbors. 


\section{References}

Burtraw, Dallas, Karen L. Palmer, Sophie Pan, , and Anthony Paul. 2015. "A Proximate Mirror: Greenhouse Gas Rules and Strategic Behavior under the US Clean Air Act." Resources for the Future.

Bushnell, James, and Yihsu Chen. 2012. "Allocation and leakage in regional cap-andtrade markets for CO2." Resources and Energy Economics, 34(4): 647-668.

Bushnell, James, Carla Peterman, and Catherine Wolfram. 2008. "Local Solutions to Global Problems: Climate Change Policies and Regulatory Jurisdiction." Review of Environmental Economics and Policy, 2(2): 175-193.

Bushnell, James, Yihsu Chen, and Matthew Zaragoza-Watkins. 2014. "Downstream regulation of CO2 emissions in California's electricity sector." Energy Policy, 64: 313-323.

Chen, Yihsu. 2009. "Does a regional greenhouse gas policy make sense? A case study of carbon leakage and emissions spillover." Energy Economics, 31(5): 667-675.

Fischer, Carolyn. 2003. "Combining rate-based and cap-and-trade emissions policies." Climate Policy, 3(S2): S89-S103.

Fowlie, Meredith L. 2009. "Incomplete environmental regulation, imperfect competition, and emissions leakage." American Economic Journal: Economic Policy, 1(2): 72-112.

Helfand, Gloria E. 1991. "Standards versus Standards: The Effects of Different Pollution Restrictions." The American Economic Review, 81(3): 622-634.

Holland, Stephen P. 2012. "Emissions taxes versus intensity standards: Second-best environmental policies with incomplete regulation." Journal of Environmental Economics and Management, 63(3): 375 - 387.

Holland, Stephen P., Jonathan E. Hughes, and Christopher R. Knittel. 2009. "Greenhouse Gas Reductions under Low Carbon Fuel Standards?" American Economic Journal: Economic Policy, 1(1): 106-46.

Holland, Stephen P., Jonathan E. Hughes, Christopher R. Knittel, and Nathan C. Parker. Forthcoming. "Some Inconvenient Truths About Climate Change Policy: The Distributional Impacts of Transportation Policies." Review of Economics and Statistics. 
Huang, Haixiao, Madhu Khanna, Hayri nal, and Xiaoguang Chen. 2013. "Stacking low carbon policies on the renewable fuels standard: Economic and greenhouse gas implications." Energy Policy, 56(0): 5 - 15.

Ito, Koichiro. 2014. "Do Consumers Respond to Marginal or Average Price? Evidence from Nonlinear Electricity Pricing." American Economic Review, 104(2): 537-63.

Kamerschen, David R, and David V Porter. 2004. "The demand for residential, industrial and total electricity, 1973-1998." Energy Economics, 26(1): 87-100.

Kwoka, John E., Jr. 1983. "The Limits of Market-Oriented Regulatory Techniques: The Case of Automotive Fuel Economy." The Quarterly Journal of Economics, 98(4): 695-704.

Newell, Richard G, William A. Pizer, and Daniel Raimi. 2012. "Carbon Markets: Past, Present, and Future." National Bureau of Economic Research.

Pizer, William A. 2005. "The case for intensity targets." Climate Policy, 5(4): 455-462.

Reiss, Peter C, and Matthew W White. 2005. "Household electricity demand, revisited." The Review of Economic Studies, 72(3): 853-883.

Stavins, Robert N. 2008. "Meaningful US Cap-and-Trade System to Address Climate Change, A." Harv. Envtl. L. Rev., 32: 293.

Taylor, Lester D. 1975. "The demand for electricity: a survey." The Bell Journal of Economics, 74-110.

Zilberman, David, Gal Hochman, Deepak Rajagopal, Steve Sexton, and Govinda Timilsina. 2013. "The Impact of Biofuels on Commodity Food Prices: Assessment of Findings." American Journal of Agricultural Economics, 95(2): 275-281. 
Tables 


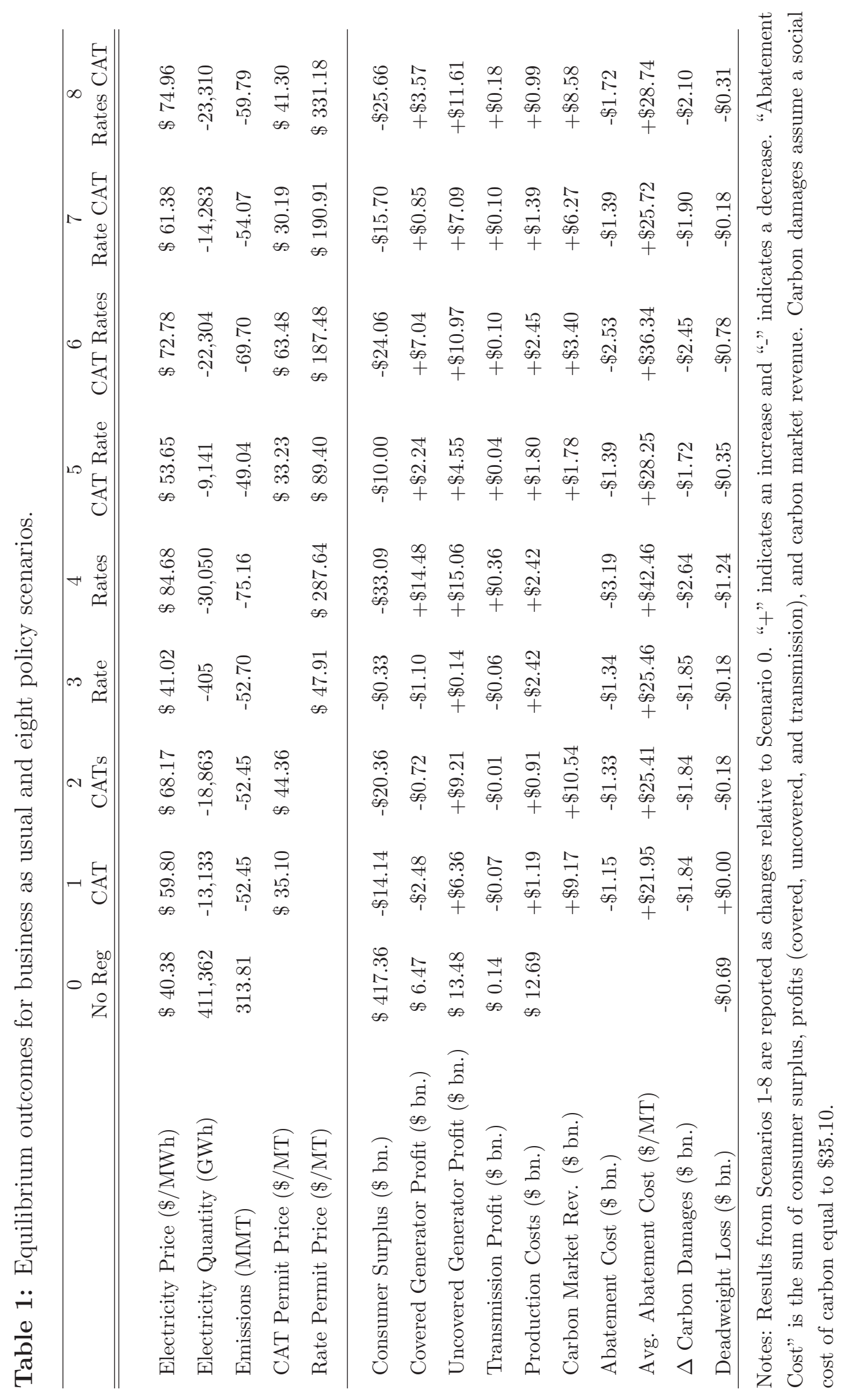




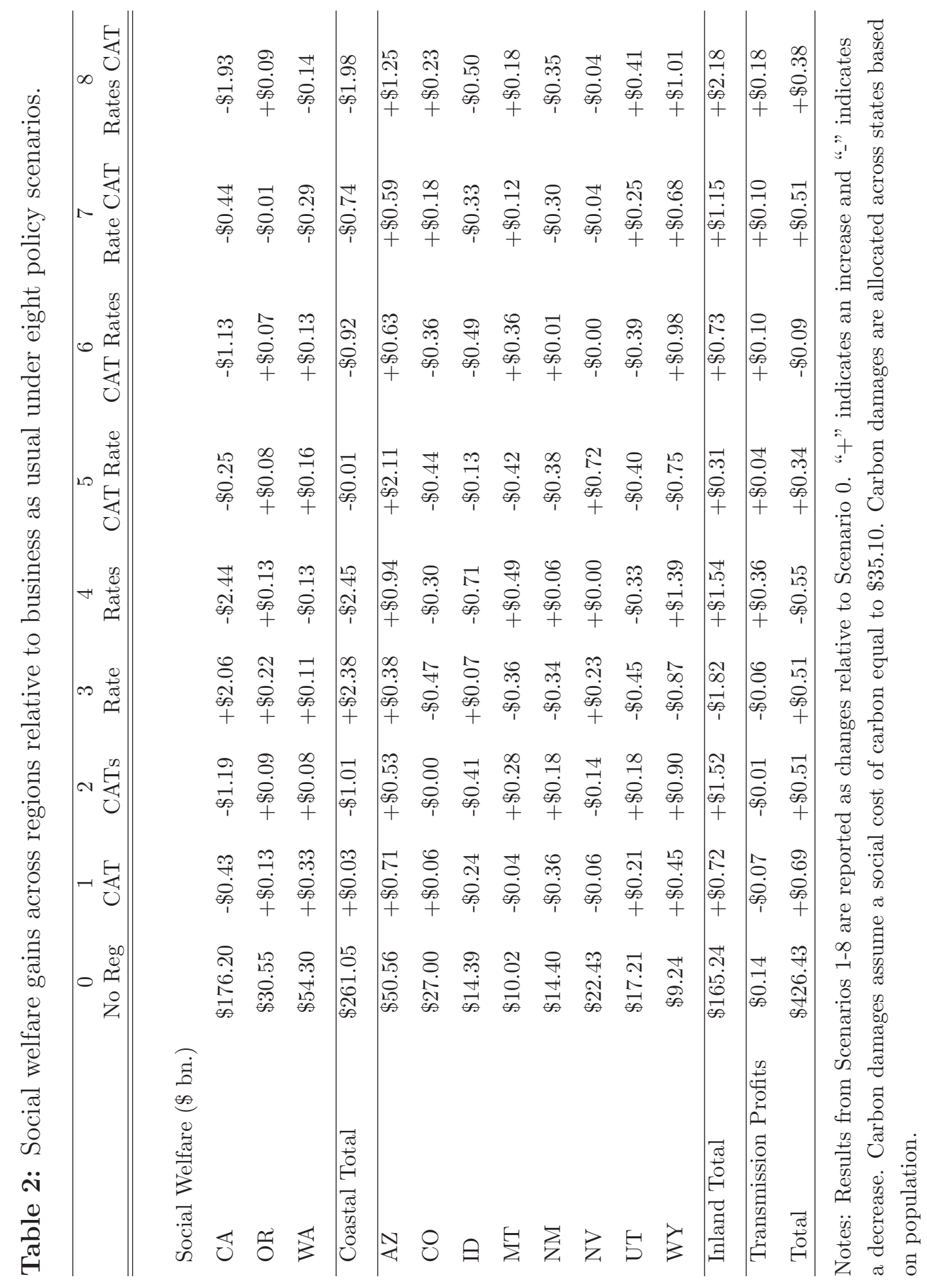







Table 4: Abatement cost incentives in the coastal and inland west.

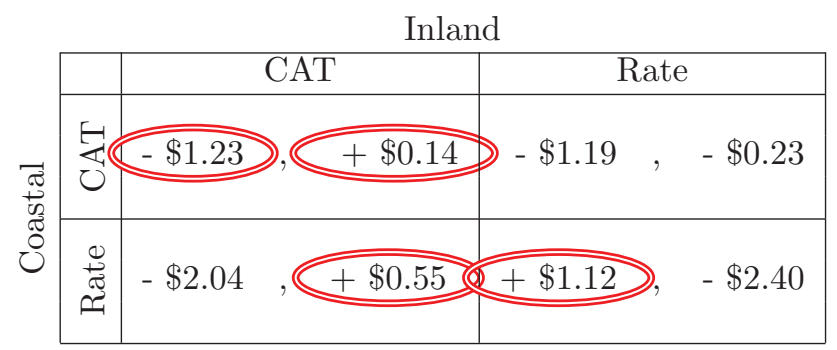

Notes: "Abatement Cost" is the sum of consumer surplus, generator profits (covered and uncovered), and carbon market revenue and is measured relative to business as usual (Scenario 0) in \$ billion. "+" indicates an increase (i.e., a gain) and "“" indicates a decrease (i.e., a loss).

Table 5: Consumer surplus incentives in the coastal and inland west.



Notes: Consumer surplus is measured relative to business as usual (Scenario 0) in \$ billion. "+" indicates an increase and "-" indicates a decrease.

Table 6: Profit incentives for all generation (covered and uncovered) in the coastal and inland west.



Notes: Profit is measured relative to business as usual (Scenario 0) in $\$$ billion. "+" indicates an increase and "." indicates a decrease. 


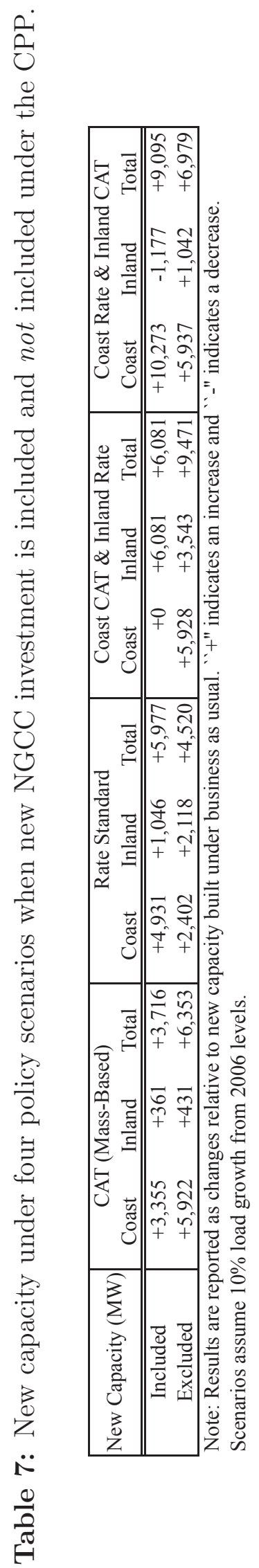




\section{Figures}

Figure 1: Full marginal costs under different regulatory regimes.

a.

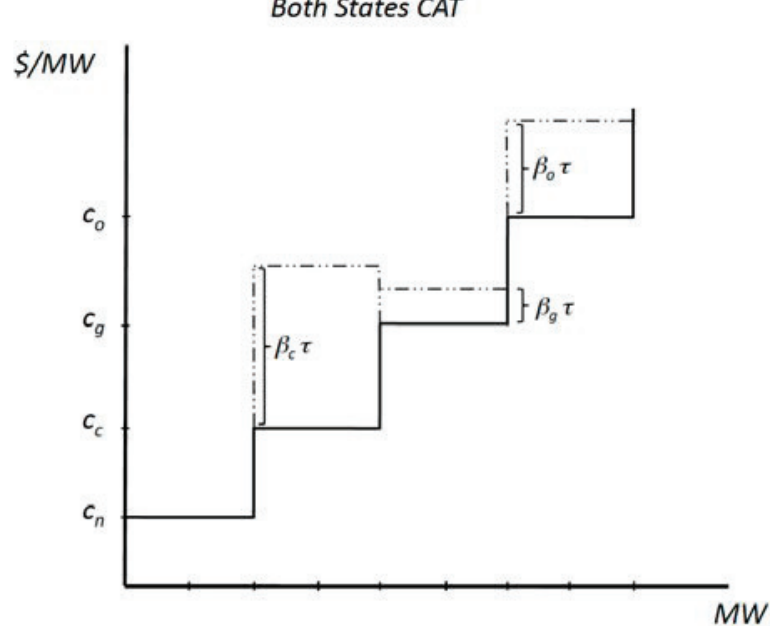

c.)

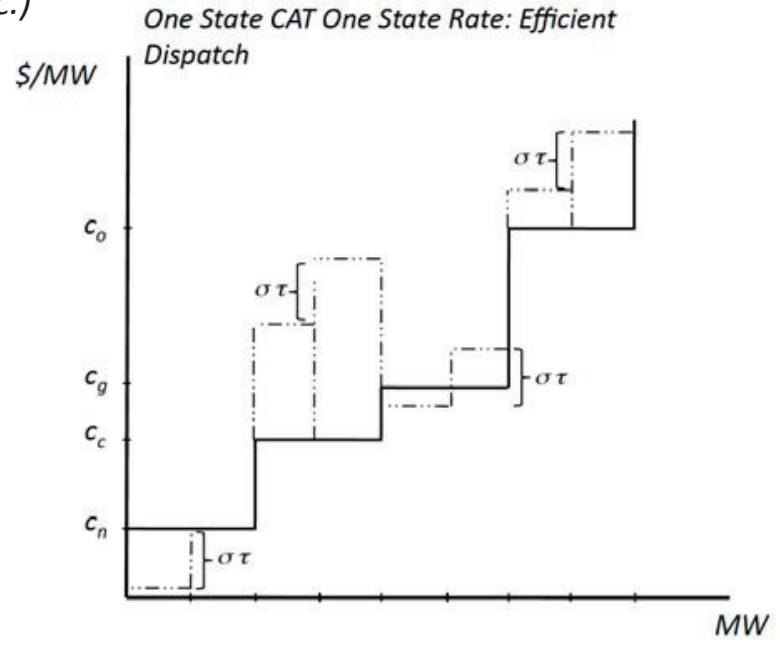

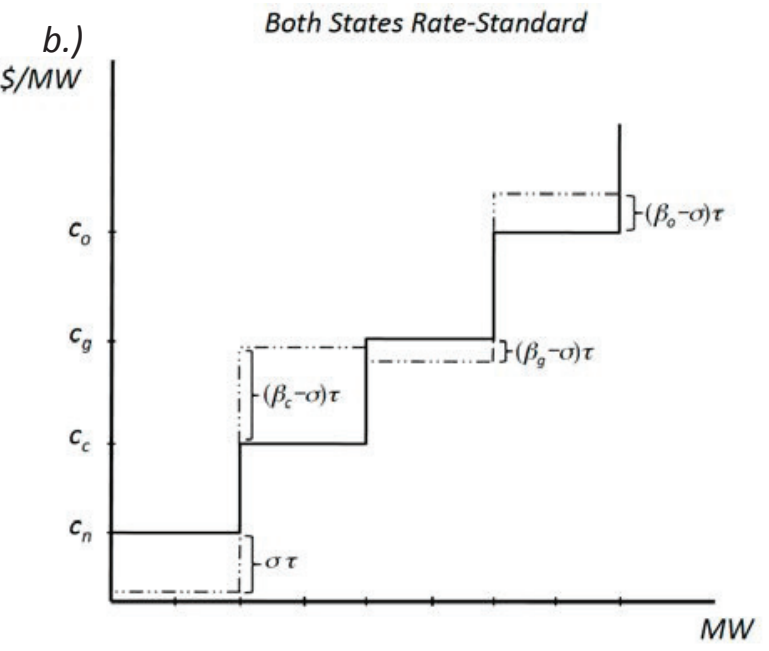

d.) One State CAT One State Rate: Inefficient

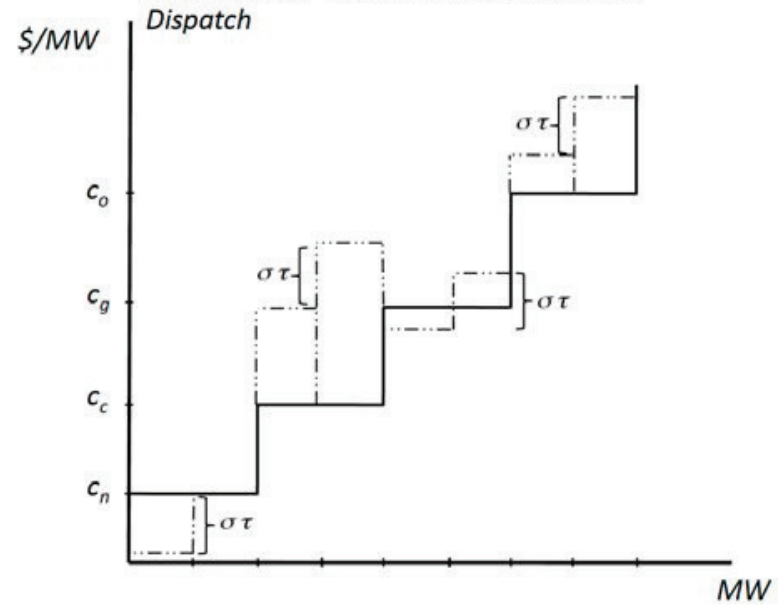


Figure 2: Merit order under different regulations: BAU and West-wide CAT and rate standards.

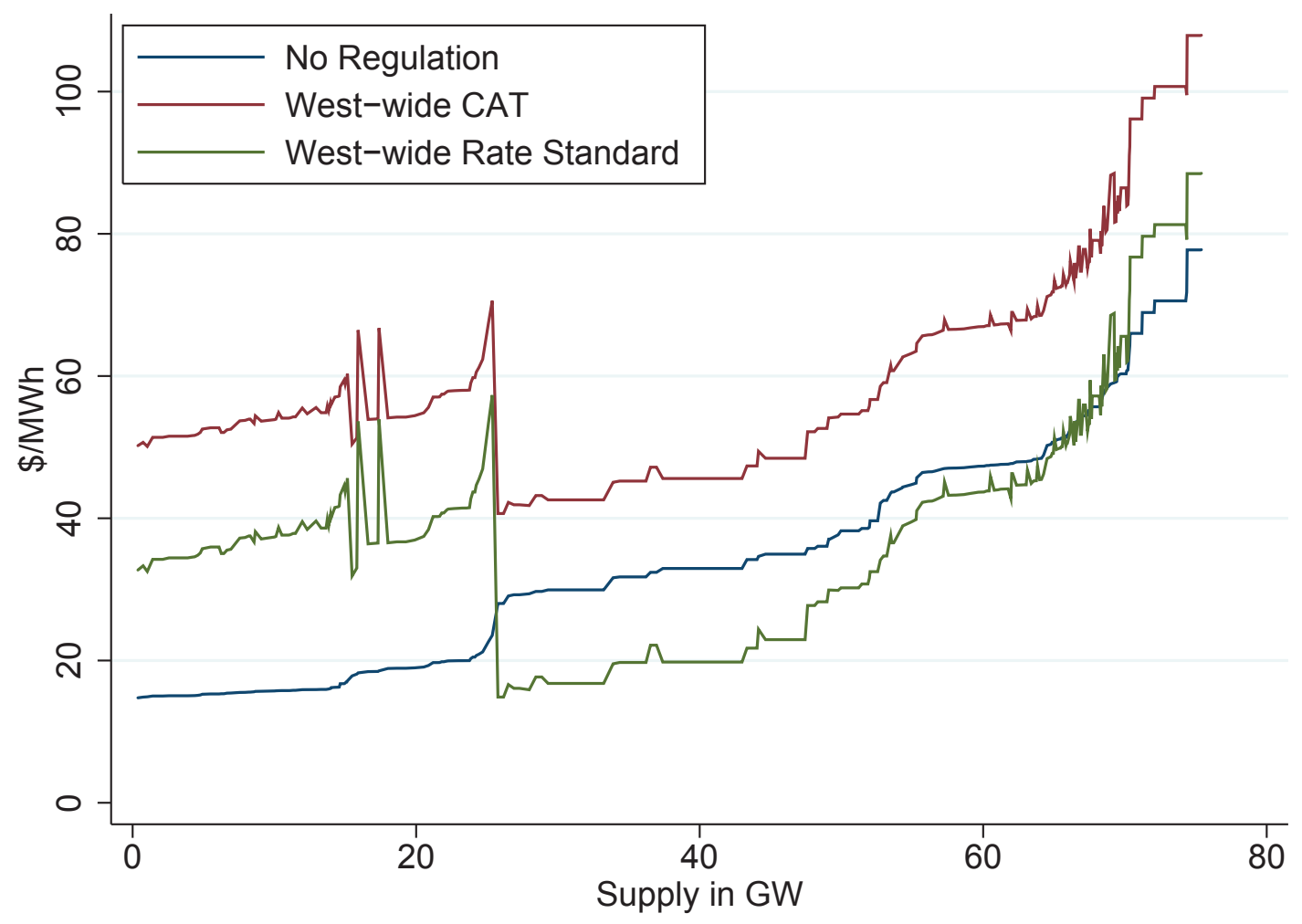

Note: Generating units sorted on x-axis by marginal costs under BAU (Scenario 0). 
Figure 3: Merit order under different regulations: West-wide CAT standards and state-bystate CAT standards.



Note: Generating units sorted on x-axis by full-marginal costs under West-wide CAT standards (Scenario 1). 
Figure 4: Merit order under different regulations: West-wide CAT standards and mixed regulation.

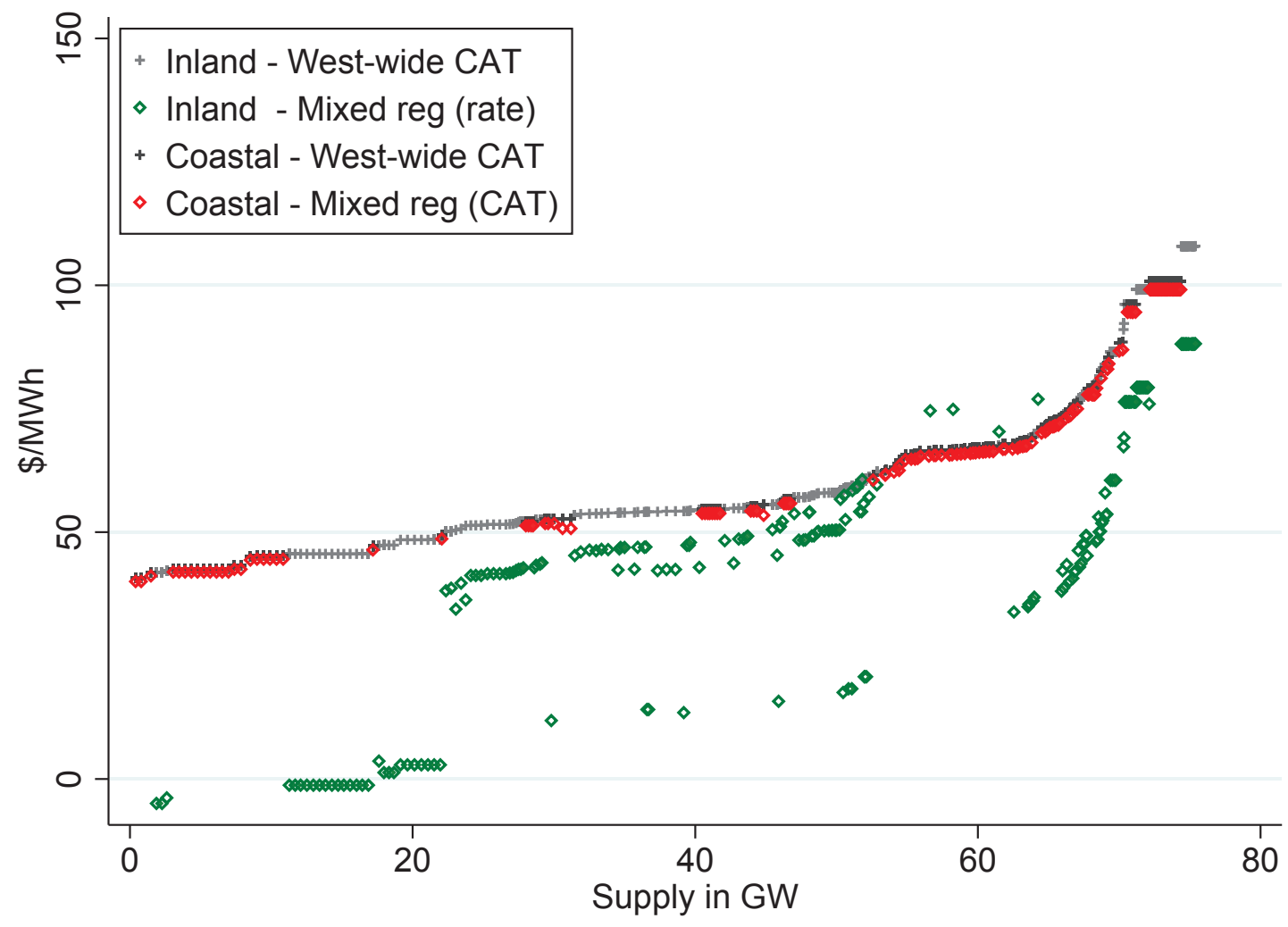

Note: Generating units sorted on x-axis by full-marginal costs under West-wide CAT standards (Scenario 1). Mixed regulation has Coastal CAT standard and Inland rate standard. 